\title{
The Macroeconomy and the Yield Curve: A Dynamic Latent Factor Approach
}

\author{
Francis X. Diebold \\ University of Pennsylvania and NBER \\ fdiebold@sas.upenn.edu \\ Glenn D. Rudebusch \\ Federal Reserve Bank of San Francisco \\ glenn.rudebusch@sf.frb.org \\ S. Boragan Aruoba \\ University of Pennsylvania \\ aruoba@econ.upenn.edu
}

This revision/print: May 19, 2004

\begin{abstract}
We estimate a model that summarizes the yield curve using latent factors (specifically, level, slope, and curvature) and also includes observable macroeconomic variables (specifically, real activity, inflation, and the monetary policy instrument). Our goal is to provide a characterization of the dynamic interactions between the macroeconomy and the yield curve. We find strong evidence of the effects of macro variables on future movements in the yield curve and evidence for a reverse influence as well. We also relate our results to the expectations hypothesis.
\end{abstract}

$\underline{\text { Key Words: }}$ Term structure, interest rates, macroeconomic fundamentals, factor model, state-space model

JEL Codes: G1, E4, C5

Acknowledgments: We thank the Editor (Giampiero Gallo) and two referees for insightful guidance. We thank the Guggenheim Foundation, the National Science Foundation, and the Wharton Financial Institutions Center for research support. Finally, we thank Andrew Ang, Pierluigi Balduzzi, Todd Clark, Ron Gallant, Ken Nyholm, Monika Piazzesi, Mike Wickens, Scott Weiner, and discussants and participants at many seminars and conferences, for helpful comments. The views expressed in this paper do not necessarily reflect those of the Federal Reserve Bank of San Francisco.

Copyright (C) 2002-2004 F.X. Diebold, G.D. Rudebusch and S.B. Aruoba. The latest version of this paper is available on the World Wide Web at http://www.ssc.upenn.edu/ fdiebold and may be freely reproduced for educational and research purposes, so long as it is not altered, this copyright notice is reproduced with it, and it is not sold for profit. 


\section{Introduction}

Macroeconomists, financial economists, and market participants all have attempted to build good models of the yield curve, yet the resulting models are very different in form and fit. In part, these differences reflect the particular modeling demands of various researchers and their different motives for modeling the yield curve (e.g., interest rate forecasting or simulation, bond or option pricing, or market surveillance). Still, an unusually large gap is apparent between the yield curve models developed by macroeconomists, which focus on the role of expectations of inflation and future real economic activity in the determination of yields, and the models employed by financial economists, which eschew any explicit role for such determinants. This paper takes a step toward bridging this gap by formulating and estimating a yield curve model that integrates macroeconomic and financial factors.

Many other recent papers have also modeled the yield curve, and they can be usefully categorized by the extent and nature of the linkages permitted between financial and macroeconomic variables. Many yield curve models simply ignore macroeconomic linkages. Foremost among these are the popular factor models that dominate the finance literature - especially those that impose a no-arbitrage restriction. For example, Knez, Litterman, and Scheinkman (1994), Duffie and Kan (1996), and Dai and Singleton (2000) all consider models in which a handful of unobserved factors explain the entire set of yields. These factors are often given labels such as "level," "slope," and "curvature," but they are not linked explicitly to macroeconomic variables.

Our analysis also uses a latent factor model of the yield curve, but we also explicitly incorporate macroeconomic factors. In this regard, our work is more closely related to Ang and Piazzesi (2003), Hördahl, Tristani, and Vestin (2002), and Wu (2002), who explicitly incorporate macro determinants into multi-factor yield curve models. However, those papers only consider a unidirectional macro linkage, because output and inflation are assumed to be determined independently of the shape of the yield curve, but not vice versa. This same assumption is made in the vector autoregression (VAR) analysis of Evans and Marshall $(1998,2001)$ where neither contemporaneous nor lagged bond yields enter the equations driving the economy. In contrast to this assumption of a one-way macro-to-yields link, the opposite view is taken in another large literature typified by Estrella and Hardouvelis (1991) and Estrella and Mishkin (1998), which assumes a yields-to-macro link and focuses only on the unidirectional predictive power of the yield curve for the economy. The two assumptions of these literatures - one-way yields-to-macro or macro-to-yields links - are testable hypotheses that are special cases of our model and are examined below. Indeed, we are particularly interested in analyzing the potential bidirectional feedback from the yield curve to the economy and back again. Some of the work closest to our own allows a feedback from an implicit inflation target derived from the yield curve to help determine the dynamics of the macroeconomy, such as Kozicki and Tinsley (2001), Dewachter and Lyrio (2002), and Rudebusch and 
$\mathrm{Wu}$ (2003). In our analysis, we allow for a more complete set of interactions in a general dynamic, latent factor framework.

Our basic framework for the yield curve is a latent factor model, although not the usual noarbitrage factor representation typically used in the finance literature. Such no-arbitrage factor models often appear to fit the cross-section of yields at a particular point in time, but they do less well in describing the dynamics of the yield curve over time (e.g., Duffee, 2002; Brousseau, 2002). Such a dynamic fit is crucial to our goal of relating the evolution of the yield curve over time to movements in macroeconomic variables. To capture yield curve dynamics, we use a three-factor term structure model based on the classic contribution of Nelson and Siegel (1987), interpreted as a model of level, slope, and curvature, as in Diebold and Li (2002). This model has the substantial flexibility required to match the changing shape of the yield curve, yet it is parsimonious and easy to estimate. We do not explicitly enforce the no-arbitrage restriction. However, to the extent that it is approximately satisfied in the dataas is likely for the U.S. Treasury bill and bond obligations that we study - it will also likely be approximately satisfied in our estimates, as our model is quite flexible and gave a very good fit to the data. Of course, there may be a loss of efficiency in not imposing the restriction of no arbitrage if it is valid, but this must be weighed against the possibility of misspecification if transitory arbitrage opportunities are not eliminated immediately.

In section 2, we describe and estimate a basic "yields-only" version of our model - that is, a model of just the yield curve without macroeconomic variables. To estimate this model, we introduce a unified state space modeling approach that lets us simultaneously fit the yield curve at each point in time and estimate the underlying dynamics of the factors. This one-step approach improves upon the two-step estimation procedure of Diebold and Li (2002) and provides a unified framework in which to examine the yield curve and the macroeconomy.

In section 3, we incorporate macroeconomic variables and estimate a "yields-macro" model. To complement the nonstructural nature of our yield curve representation, we also use a simple nonstructural VAR representation of the macroeconomy. The focus of our examination is the nature of the linkages between the factors driving the yield curve and macroeconomic fundamentals.

In section 4, we relate our framework to the expectations hypothesis, which has been studied intensively in macroeconomics. The expectation hypotheses of the term structure is a special case of our model that receives only limited support.

We offer concluding remarks in section 5.

\section{A Yield Curve Model Without Macro Factors}


In this section, we introduce a factor model of the yield curve without macroeconomic variables, which is useful for two key reasons. First, methodologically, such a model proves to be a convenient vehicle for introducing the state-space framework that we use throughout the paper. Second, and substantively, the estimated yields-only model serves as a useful benchmark to which we subsequently compare our full model that incorporates macroeconomic variables.

\subsection{A Factor Model Representation}

The factor model approach expresses a potentially large set of yields of various maturities as a function of just a small set of unobserved factors. Denote the set of yields as $y(\tau)$, where $\tau$ denotes maturity. Among practitioners and especially central banks, ${ }^{1}$ a very popular representation of the crosssection of yields at any point in time is the Nelson and Siegel (1987) curve:

$$
y(\tau)=\beta_{1}+\beta_{2}\left(\frac{1-e^{-\lambda \tau}}{\lambda \tau}\right)+\beta_{3}\left(\frac{1-e^{-\lambda \tau}}{\lambda \tau}-e^{-\lambda \tau}\right),
$$

where $\beta_{1}, \beta_{2}, \beta_{3}$ and $\lambda$ are parameters. ${ }^{2}$ Moreover, as shown by Diebold and Li (2002), the NelsonSiegel representation can be interpreted in a dynamic fashion as a latent factor model in which $\beta_{1}, \beta_{2}$, and $\beta_{3}$ are time-varying level, slope, and curvature factors and the terms that multiply these factors are factor loadings. ${ }^{3}$ Thus, we write

$$
y_{t}(\tau)=L_{t}+S_{t}\left(\frac{1-e^{-\lambda \tau}}{\lambda \tau}\right)+C_{t}\left(\frac{1-e^{-\lambda \tau}}{\lambda \tau}-e^{-\lambda \tau}\right),
$$

where $L_{t}, S_{t}$, and $C_{t}$ are the time-varying $\beta_{1}, \beta_{2}$, and $\beta_{3}$. We illustrate this interpretation with our empirical estimates below.

If the dynamic movements of $L_{t} S_{t}$, and $C_{t}$ follow a vector autoregressive process of first order,

${ }^{1}$ As described in documentation from the Bank for International Settlements (1999), many central banks have adopted the Nelson-Siegel yield curve (or some slight variant) for fitting bond yields.

${ }^{2}$ Our Nelson-Siegel yield curve (1) corresponds to equation (2) of Nelson Siegel (1987). Their notation differs from ours in a potentially confusing way: they use $m$ for maturity and $1 / \tau$ for the constant $\lambda$.

${ }^{3}$ More precisely, Diebold and Li show that $\beta_{2}$ corresponds to the negative of slope as traditionally defined ("long minus short yields"). For ease of discussion, we prefer simply to call $\beta_{2}$, and hence $S_{t}$, "slope," so we define slope as "short minus long." 
then the model immediately forms a state-space system. ${ }^{4}$ The transition equation, which governs the dynamics of the state vector, is

$$
\left(\begin{array}{c}
L_{t}-\mu_{L} \\
S_{t}-\mu_{S} \\
C_{t}-\mu_{C}
\end{array}\right)=\left(\begin{array}{lll}
a_{11} & a_{12} & a_{13} \\
a_{21} & a_{22} & a_{23} \\
a_{31} & a_{32} & a_{33}
\end{array}\right)\left(\begin{array}{c}
L_{t-1}-\mu_{L} \\
S_{t-1}-\mu_{S} \\
C_{t-1}-\mu_{C}
\end{array}\right)+\left(\begin{array}{c}
\eta_{t}(L) \\
\eta_{t}(S) \\
\eta_{t}(C)
\end{array}\right),
$$

$t=1, \ldots, T$. The measurement equation, which relates a set of $N$ yields to the three unobservable factors, is

$$
\left(\begin{array}{c}
y_{t}\left(\tau_{1}\right) \\
y_{t}\left(\tau_{2}\right) \\
\vdots \\
y_{t}\left(\tau_{N}\right)
\end{array}\right)=\left(\begin{array}{ccc}
1 & \frac{1-e^{-\tau_{1} \lambda}}{\tau_{1} \lambda} & \frac{1-e^{-\tau_{1} \lambda}}{\tau_{1} \lambda}-e^{-\tau_{1} \lambda} \\
1 & \frac{1-e^{-\tau_{2} \lambda}}{\tau_{2} \lambda} & \frac{1-e^{-\tau_{2} \lambda}}{\tau_{2} \lambda}-e^{-\tau_{2} \lambda} \\
\vdots & \vdots & \vdots \\
1 & \frac{1-e^{-\tau_{N} \lambda}}{\tau_{N} \lambda} & \frac{1-e^{-\tau_{N} \lambda}}{\tau_{N} \lambda}-e^{-\tau_{N} \lambda}
\end{array}\right)\left(\begin{array}{c}
L_{t} \\
S_{t} \\
C_{t}
\end{array}\right)+\left(\begin{array}{c}
\varepsilon_{t}\left(\tau_{1}\right) \\
\varepsilon_{t}\left(\tau_{2}\right) \\
\vdots \\
\varepsilon_{t}\left(\tau_{N}\right)
\end{array}\right),
$$

$t=1, \ldots, T$. In an obvious vector/matrix notation, we write this state-space system as

$$
\begin{aligned}
& \left(f_{t}-\mu\right)=A\left(f_{t-1}-\mu\right)+\eta_{t} \\
& y_{t}=\Lambda f_{t}+\varepsilon_{t} .
\end{aligned}
$$

For linear least squares optimality of the Kalman filter, we require that the white noise transition and measurement disturbances be orthogonal to each other and to the initial state:

$$
\left(\begin{array}{c}
\eta_{t} \\
\varepsilon_{t}
\end{array}\right) \sim W N\left[\left(\begin{array}{l}
0 \\
0
\end{array}\right),\left(\begin{array}{ll}
Q & 0 \\
0 & H
\end{array}\right)\right]
$$

${ }^{4}$ As is well-known, ARMA state vector dynamics of any order may be readily accommodated in state-space form. We maintain the VAR(1) assumption only for transparency and parsimony. 


$$
\begin{aligned}
& E\left(f_{0} \eta_{t}^{\prime}\right)=0 \\
& E\left(f_{0} \varepsilon_{t}^{\prime}\right)=0 .
\end{aligned}
$$

In much of our analysis, we assume that the $H$ matrix is diagonal and the $Q$ matrix is non-diagonal. The assumption of a diagonal $H$ matrix, which implies that the deviations of yields of various maturities from the yield curve are uncorrelated, is quite standard. For example, in estimating the no-arbitrage term structure models, i.i.d. "measurement error" is typically added to the observed yields. This assumption is also required for computational tractability given the large number of observed yields used. The assumption of an unrestricted $Q$ matrix, which is potentially non-diagonal, allows the shocks to the three term structure factors to be correlated.

In general, state-space representations provide a powerful framework for analysis and estimation of dynamic models. The recognition that the Nelson-Siegel form is easily put in state-space form is particularly useful because application of the Kalman filter then delivers maximum-likelihood estimates and optimal filtered and smoothed estimates of the underlying factors. In addition, the one-step Kalman filter approach of this paper is preferable to the two-step Diebold-Li approach, because the simultaneous estimation of all parameters produces correct inference via standard theory. The two-step procedure, in contrast, suffers from the fact that the parameter estimation and signal extraction uncertainty associated with the first step is not acknowledged in the second step. Finally, the state-space representation paves the way for possible future extensions, such as allowance for heteroskedasticty, missing data, and heavytailed measurement errors, although we do not pursue those extensions in the present paper.

At this point, it is also perhaps useful to explicitly contrast our approach with others that have been used in the literature. A completely general (linear) model of yields would be an unrestricted VAR estimated for a set of yields. One potential drawback to such a representation is that the results may depend on the particular set of yields chosen. A factor representation, as above, can aggregate information from a large set of yields. One straightforward factor model is a VAR estimated with the principal components formed from a large set of yields. (See Evans and Marshall 1998, 2001 for VAR term structure analyses.) Such an approach restricts the factors to be orthogonal to each other but does not restrict the factor loadings at all. In contrast, our model allows correlated factors but restricts the factor loadings through limitations on the set of admissible yield curves. For example, the Nelson-Siegel form guarantees positive forward rates at all horizons and a discount factor that approaches zero as maturity increases. Such economically-motivated restrictions likely aid in the analysis of yield curve 
dynamics. ${ }^{5}$ Alternative restrictions could also be imposed. The most popular alternative is the noarbitrage restriction, which enforces the consistency of the evolution of the yield curve over time with the absence of arbitrage opportunities. However, there is mixed evidence on the extent to which these restrictions enhance inference. (Compare, for example, Ang and Piazzesi, 2003 and Duffee, 2002.) 2.2 Yields-Only Model Estimation

We examine U.S. Treasury yields with maturities of 3, 6, 9, 12, 15, 18, 21, 24, 30, 36, 48, 60, 72, 84, 96, 108 and 120 months. The yields are derived from bid/ask average price quotes, from January 1972 through December 2000, using the unsmoothed Fama-Bliss (1987) approach, as described in Diebold and Li (2002). They are measured as of the beginning of each month; this timing convention is immaterial for the yields-only model but will be more important when macro variables are introduced.

As discussed above, the yields-only model forms a state-space system, with a VAR(1) transition equation summarizing the dynamics of the vector of latent state variables, and a linear measurement equation relating the observed yields to the state vector. Several parameters must be estimated. The (3x3) transition matrix $A$ contains 9 free parameters, the $(3 \times 1)$ mean state vector $\mu$ contains 3 free parameters, and the measurement matrix $\Lambda$ contains 1 free parameter, $\lambda$. Moreover, the transition and disturbance covariance matrix $Q$ contains 6 free parameters (one disturbance variance for each of the three latent level, slope and curvature factors and three covariance terms), and the measurement disturbance covariance matrix $H$ contains seventeen free parameters (one disturbance variance for each of the seventeen yields). All told, then, 36 parameters must be estimated by numerical optimization - a challenging, but not insurmountable, numerical task.

For a given parameter configuration, we use the Kalman filter to compute optimal yield predictions and the corresponding prediction errors, after which we proceed to evaluate the Gaussian likelihood function of the yields-only model using the prediction-error decomposition of the likelihood. We initialize the Kalman filter using the unconditional mean (zero) and unconditional covariance matrix of the state vector. ${ }^{6}$ We maximize the likelihood by iterating the Marquart and Berndt-Hall-HallHausman algorithms, using numerical derivatives, optimal stepsize, and a convergence criterion of $10^{-6}$

${ }^{5}$ Accumulated experience - as well as formal Bayes/Stein theory - leads naturally to the celebrated parsimony or shrinkage principle as a strategy for avoiding data mining and in-sample overfitting. This is the broad insight that imposition of sensible restrictions, which must of course degrade in-sample fit, is often a crucial ingredient for the production of useful models for analysis and forecasting.

${ }^{6}$ For details of Kalman filtering and related issues such as initialization of the filter, see Harvey (1981) or Durbin and Koopman (2001). 
for the change in the norm of the parameter vector from one iteration to the next. We impose nonnegativity on all estimated variances by estimating log variances; then we convert to variances by exponentiating and compute asymptotic standard errors using the delta method. We obtain startup parameter values by using the Diebold-Li two-step method to obtain the initial transition equation matrix, initializing all variances at 1.0, and initializing $\lambda$ at the value given in Diebold and Li (2002).

In the first panel of Table 1 we present estimation results for the yields-only model. The estimate of the $A$ matrix indicates highly persistent own dynamics of $L_{t}, S_{t}$, and $C_{t}$, with estimated own-lag coefficients of $.99, .94$ and .84 , respectively. Cross-factor dynamics appear unimportant, with the exception of a minor but statistically significant effect of $S_{t-1}$ on $L_{t}$. The estimates also indicate that persistence decreases (as measured by the diagonal elements of $A$ ), and transition shock volatility increases (as measured by the diagonal elements of $Q$ ), as we move from $L_{t}$ to $S_{t}$ to $C_{t}$. The remaining estimates appear sensible; the mean level is approximately 8 percent, the mean slope is approximately 1.5 percent, and the mean curvature is insignificantly different from $0 .{ }^{7}$ In the second and third panel of Table 1 we report the estimated $Q$ matrix and two tests of its diagonality. There is only one individuallysignificant covariance term, and the off-diagonal elements of the matrix (tested jointly as a group) are only marginally significant. ${ }^{8}$ Finally, the estimated $\lambda$ of .077 implies that the loading on the curvature factor is maximized at a maturity of 23.3 months.

The yields-only model fits the yield curve remarkably well. The first two columns of Table 2 contain the estimated means and standard deviations of the measurement equation residuals, expressed in basis points, for each of the seventeen maturities that we consider. The mean error is negligible at all maturities (with the possible exception of 3 months), and in the crucial middle range of maturities from 6 to 60 months, the average standard deviation is just 8.7 basis points. The average standard deviation increases at very short and very long maturities but nevertheless remains quite small. ${ }^{9}$

We use the Kalman smoother to obtain optimal extractions of the latent level, slope and curvature factors. In Figure 1, we plot these three estimated factors together for comparative assessment, and in

${ }^{7}$ Recall that we define slope as short minus long, so that a negative mean slope means that yields tend to increase as maturity lengthens.

${ }^{8}$ Not surprisingly, when we estimate the model with the restriction that the $Q$ matrix is diagonal, the point estimates and standard errors of the elements of the $A$ matrix are little changed from Table 1.

${ }^{9}$ As an additional check of model adequacy, we also tried four-factor and five-factor extended models, as in Björk and Christensen (1999). The extensions provided negligible improvement in model fit. These results are consistent with Dahlquist and Svensson (1994) who compare the Nelson and Siegel model with a more complex functional form and also find no improvement to using the latter. 
Figures 2, 3, and 4 we plot the respective factors in isolation of each other, but together with various empirical proxies and potentially related macroeconomic variables. ${ }^{10}$

The level factor displays very high persistence in Figure 1and is of course positive - in the neighborhood of 8 percent. In contrast, the slope and curvature are less persistent and assume both positive and negative values. The unconditional variances of the slope and curvature factors are roughly equal but are composed differently: slope has higher persistence and lower shock variance, whereas curvature has lower persistence and higher shock variance. Interestingly, slope and curvature appear related at business cycle frequencies. The simple correlation is 0.25 , but the correlation at business cycle frequencies is 0.55 and at very low frequencies is $-0.07 .{ }^{11}$

In Figure 2 we show the estimated level and two closely-linked comparison series: a common empirical proxy for level (namely, an average of short-, medium- and long-term yields, $\left.\left(y_{t}(3)+y_{t}(24)+y_{t}(120)\right) / 3\right)$, and a measure of inflation (the 12-month percent change in the price deflator $\left(P_{t}\right)$ for personal consumption expenditures, namely, $\left.100 *\left(P_{t}-P_{t-12}\right) / P_{t-12}\right)$. The high .80 correlation between $\hat{L}_{t}$ and $\left(y_{t}(3)+y_{t}(24)+y_{t}(120)\right) / 3$ supports our interpretation of $L_{t}$ as a level factor. The correlation between $\hat{L}_{t}$ and actual inflation, which is .43 , is consistent with a link between the level of the yield curve and inflationary expectations, as suggested by the Fisher equation. This link is a common theme in the recent macro-finance literature, including Kozicki and Tinsley (2001), Dewachter and Lyrio (2002), Hördahl, Tristani, and Vestin (2002), and Rudebusch and Wu (2003).

In Figure 3 we show the estimated slope and two comparison series, to which the slope factor is closely linked: a standard empirical slope proxy $\left(y_{t}(3)-y_{t}(120)\right)$, and an indicator of macroeconomic activity (demeaned capacity utilization). The high .98 correlation between $\hat{S}_{t}$ and $y_{t}(3)-y_{t}(120)$ lends credibility to our interpretation of $S_{t}$ as a slope factor. The correlation between $\hat{S}_{t}$ and capacity utilization, which is .39 , suggests that yield curve slope, like yield curve level, is intimately connected to the cyclical dynamics of the economy.

Finally, in Figure 4 we show the estimated curvature together with a standard empirical curvature proxy, $2 y_{t}(24)-y_{t}(3)-y_{t}(120)$, to which $C_{t}$ is closely linked with a correlation of .96, which again lends credibility to our interpretation of $C_{t}$ as a curvature factor. Unfortunately, as shown in our combined yields-macro model in the next section, we know of no reliable macroeconomic links to $C_{t}$.

\section{A Yield Curve Model With Macro Factors}

${ }^{10}$ In each case, the latent factor extractions are based on full-sample parameter estimates.

${ }^{11}$ More precisely, the correlation between Hodrick-Prescott "cycles" (deviations from trends) in $\beta_{2}$ and $\beta_{3}$ is 0.55 , and the correlation between Hodrick-Prescott "trends" in $\beta_{2}$ and $\beta_{3}$ is -0.07 . 
Given the ability of the level, slope, and curvature factors to provide a good representation of the yield curve, it is of interest to relate them to macroeconomic variables. This can be done readily in an expanded version of the above state-space framework. In the next five subsections, we analyze the dynamic interactions between the macroeconomy and the yield curve, and we assess their importance.

\subsection{The Yields-Macro Model: Specification and Estimation}

We wish to characterize the relationships among $\hat{L}_{t}, \hat{S}_{t}, \hat{C}_{t}$ and the macroeconomy. Our measures of the economy include three key variables: manufacturing capacity utilization $\left(C U_{t}\right)$, the federal funds rate $\left(F F R_{t}\right)$, and annual price inflation $\left(I N F L_{t}\right) .{ }^{12}$ These three variables represent, respectively, the level of real economic activity relative to potential, the monetary policy instrument, and the inflation rate, which are widely considered to be the minimum set of fundamentals needed to capture basic macroeconomic dynamics. ${ }^{13}$

A straightforward extension of the yields-only model adds the three macroeconomic variables to the set of state variables and replaces equations (5)-(7) with

$$
\begin{aligned}
& \left(f_{t}-\mu\right)=A\left(f_{t-1}-\mu\right)+\eta_{t} \\
& y_{t}=\Lambda f_{t}+\varepsilon_{t} \\
& \left(\begin{array}{l}
\eta_{t} \\
\varepsilon_{t}
\end{array}\right) \sim W N\left[\left(\begin{array}{l}
0 \\
0
\end{array}\right),\left(\begin{array}{ll}
Q & 0 \\
0 & H
\end{array}\right)\right],
\end{aligned}
$$

where $f_{t}^{\prime}=\left(L_{t}, S_{t}, C_{t}, C U_{t}, F F R_{t}, I N F L_{t}\right)$ and the dimensions of $A, \mu, \eta_{t}$ and $Q$ are increased as appropriate. ${ }^{14}$ This system forms our yields-macro model, to which we will compare our earlier yields-

${ }^{12}$ The variable $I N F L$ is the 12-month percent change in the price deflator for personal consumption expenditures, and FFR is the monthly average funds rate.

${ }^{13}$ See, for example, Rudebusch and Svensson (1999) and Kozicki and Tinsley (2001).

${ }^{14} \Lambda$ is now $N \times 6$, but the three rightmost columns contain only zeros, so that the yields still load only on the yield curve factors. This form is consistent with the view that only three factors are needed to distill the information in the yield curve. 
only model. ${ }^{15}$ Our baseline yields-macro model continues to assume a non-diagonal $Q$ matrix and a diagonal $H$ matrix. Producing impulse responses from this model requires an identification of the covariances given by the off-diagonal elements of the $Q$ matrix. Following common practice, we do this by assuming a particular recursive causal ordering of the variables; namely, we order the variables $L_{t}, S_{t}$, $C_{t}, C U_{t}, I N F L_{t}, F F R_{t}$. We order the term structure factors prior to the macro variables because they are dated at the beginning of each month. ${ }^{16}$

In the first panel of Table 3 we display the estimates of the parameters of the yields-macro model, which contains the crucial macro and term structure interactions. ${ }^{17}$ Individually, many of the off-diagonal elements appear insignificant; however, as we discuss below, key blocks of coefficients appear jointly significant. The estimated Q matrix is provided in the second panel of Table 3. Several of the offdiagonal covariances appear significant individually. The Wald and Likelihood Ratio tests reported in the third panel clearly reject the diagonality of the $Q$ matrix.

The time series of estimates of the level, slope, and curvature factors in the yields-macro model are very similar to those obtained in the yields-only model. Thus, as shown in the third and fourth columns of Table 2, the means and standard deviations of the measurement errors associated with the yields-macro model are essentially identical to those of the yields-only model. In particular, the mean errors are again negligible, and in the important 6- to 60-month maturity range, the average standard deviation is just 8.6 basis points.

\subsection{Macroeconomic and Yield Curve Impulse Response Functions}

We examine the dynamics of the complete yields-macro system by via impulse response functions, which we show in Figure 5, along with ninety percent confidence intervals. We will consider four groups of impulse responses in turn: macro responses to macro shocks, macro responses to yield curve shocks, yield curve responses to macro shocks, and yield curve responses to yield curve shocks.

The responses of the macro variables to macro shocks match the typical impulse responses

${ }^{15}$ We have maintained a first-order VAR structure for simplicity and tractability. However, based on some limited exploration of second-order models, it appears that our results are robust to this assumption as well.

${ }^{16}$ As discussed below, we also examined the robustness of our results to alternative identification strategies. In particular, we obtained similar results for a model with a diagonal $Q$ matrix, which is neutral with respect to ordering of the variables. We also obtained similar results using end-of-period yield data and ordering the variables as $C U_{t}, I N F L_{t}, F F R_{t}, L_{t}, S_{t}, C_{t}$.

${ }^{17}$ The own-lag coefficient of $C U_{t}$ rounds to 1.00 but actually is just less than one, and stationarity is assured since the largest eigenvalue of the $A$ matrix is 0.98 . 
produced in small estimated macro models of the kind commonly used in monetary policy analysis (e.g., Rudebusch and Svensson, 1999). The macro variables all show significant persistence. ${ }^{18}$ In addition, an increase in the funds rate depresses capacity utilization over the next few years, similar to the aggregate demand response in Rudebusch and Svensson (1999). The funds rate, in turn, rises with capacity utilization and - albeit with only marginal significance - with inflation in a fashion broadly consistent with an estimated Federal Reserve monetary policy reaction function. Finally, inflation exhibits a clear aggregate supply response to increased capacity utilization and, over time, declines in response to a funds rate increase. ${ }^{19}$

The yield curve components add some interesting elements to the macro responses. The macro variables have negligible responses to shocks in the curvature factor. In contrast, an increase in the slope factor is followed by an almost one-to-one response in the funds rate. That is, there is a close connection between the slope factor and the instrument of monetary policy. However, there are two interpretations of such a connection. On the one hand, the Fed may be reacting to yields (which are measured at the beginning of the month) in setting the funds rate. On the other hand, given the institutional frictions of monetary policy decision-making (e.g., the 6-week spacing between policy meetings and the requirement for committee approval), it is likely that yields are reacting to macroeconomic information in anticipation of Fed actions. That is, to the extent the Fed has established a predictable policy reaction function to macroeconomic information, movements in bond markets may often appear to predate those of the Fed.

Finally, an increase in the level factor raises capacity utilization, the funds rate, and inflation. Recall from Figure 2 the close connection between inflation and the level factor. The macro responses exhibited in Figure 5 are consistent with the above interpretation of the level factor as the bond market's perception of long-run inflation. Under this interpretation, an increase in the level factor - that is, an increase in future perceived inflation - lowers the ex ante real interest rate when measured as $F F R_{t}-L_{t}$, which is followed by a near-term economic boom. ${ }^{20}$ However, during our sample, the Fed has apparently accommodated only a small portion of the expected rise in inflation. The nominal funds rate rises

${ }^{18}$ The interpretation of the persistence of FFR - the policy rate manipulated by the Fed - is open to some debate. However, Rudebusch (2002) argues that it does not indicate "interest rate smoothing" or "monetary policy inertia"; instead, it reflects serially correlated unobserved factors to which the Fed responds.

${ }^{19}$ There is a marginally-significant initial upward response of inflation to the funds rate - a socalled "price puzzle" - which is typical in small VARs of this kind.

${ }^{20}$ An ex post $F F R_{t}-I N F L_{t}$ does not appear to be appropriate, as a positive shock to inflation does not boost economic activity (see Rudebusch and Svensson, 1999). 
significantly in response to the level shock, damping utilization, and limiting the rise in inflation to only about $40 \%$ of the initial shock to the level.

Now consider the response of the yield curve to the macro variables. While the curvature factor shows very little response, the slope factor responds directly to positive shocks in all three macro variables. For example, an increase in the funds rate almost immediately pushes up the slope factor so the yield curve is less positively sloped (or more negatively sloped). Positive shocks to utilization, and to a lesser extent inflation, also induce similar though more delayed movements in the tilt. These reactions are consistent with a monetary policy response that raises the short end of the term structure in response to positive output and inflation surprises. However, shocks to the macro variables also affect the level of the term structure. In particular, surprises to actual inflation appear to give a long-run boost to the level factor. Such a reaction is consistent with long-inflation expectations not being firmly anchored, so a surprise increase in inflation (or even in real activity) feeds through to an expectation of higher future inflation, which raises the level factor. ${ }^{21}$ A positive shock to the funds rate is also followed by a small temporary jump in the level factor. In principle, a surprise increase in the monetary policy rate could have two quite different effects on inflation expectations. On the one hand, if the central bank has a large degree of credibility and transparency, then a tightening could indicate a lower inflation target and a likely lowering of the level factor. Alternatively, a surprise tightening could indicate that the central back is worried about overheating and inflationary pressures in the economy - news that would boost future inflation expectations and the level factor. Evidently, over our sample, the later effect has dominated.

Finally, consider the block of own-dynamics of the term structure factors. The three factors exhibit significant persistence. Most off-diagonal responses are insignificant; however, a surprise increase in the level factor, which we interpret as higher inflation expectations, is associated with loosening of policy as measured by the slope factor and a lowering of the short end of the term structure relative to the long end. ${ }^{22}$

\section{$\underline{3.3 \text { Macroeconomic and Yield Curve Variance Decompositions }}$}

Variance decompositions provide a popular metric for analyzing macro and yield curve interactions. Table 4 provides variance decompositions of the 1-month, 12-month, and 60-month yields mechanism.

${ }^{21}$ Gurkaynak, Sack, and Swanson (2003) and Rudebusch and Wu (2003) discuss such a

${ }^{22}$ Overall then, in important respects, this analysis improves on the usual monetary VAR, which contains a flawed specification of monetary policy (Rudebusch, 1998). In particular, the use of level, slope, and the funds rate allows a much more subtle and flexible description of policy. 
at forecast horizons of 1, 12, and 60 months. Decompositions are provided for both the yields-only and the yields-macro models. At a 1-month horizon, very little of the variation in rates is driven by the macro factors $(8,4$, and 2 percent for the 1-month, 12-month, and 60-month yield, respectively). This suggests a large amount of short-term idiosyncratic variation in the yield curve that is unrelated to macroeconomic fundamentals. However, at longer horizons, the macro factors quickly become more influential, and at a 60 -month horizon, they account for about 40 percent of the variation in rates. This contribution is similar to the results in Ang and Piazzesi's (2003) macro model. A comparison of yields-only and yields-macro decompositions shows that the variance accounted for by the slope factor falls notably with the addition of the macro variables. That is, movements in yields that had been attributed to shocks to slope are now traced to shocks to output, inflation, and monetary policy. ${ }^{23}$ In contrast, the variance contributions from level and curvature are little changed on balance.

Table 5 examines the variance decompositions for the macroeconomic variables based on the joint yields-macro model and a "macro-only" model, which is a simple first-order VAR for CU, FFR, INFL. In the yields-macro model, the term structure factors account for very little of the variation in capacity utilization or inflation. Yield curve factors do predict a substantial fraction of movements in the funds rate, but as noted above, this may reflect the adjustment of bond markets to new information before the Fed can react.

Taken together, the variance decompositions suggest that the effects of the yield curve on the macro variables are less important than the effects of the macro variables on the yield curve. To interpret this result correctly, it is important to note that an interest rate - the federal funds rate - is also included among the macro variables. That is, we are asking what would the yield curve add to a standard small macro model, such as the Rudebusch-Svensson (1999) model. We are not arguing that interest rates do not matter, but that, for our specification and sample, the funds rate is perhaps, to a rough approximation, a sufficient statistic for interest rate effects in macro dynamics, which is a conclusion consistent with Ang, Piazzesi, and Wei (2003).

\section{$\underline{3.4 \text { Formal Tests of Macro and Yield Curve Interactions }}$}

The coefficient matrix $A$ and the covariance matrix $Q$ shown in Table 3 are crucial for assessing interactions between macroeconomic variables and the term. We begin by partitioning the $6 \times 6 \mathrm{~A}$ matrix into four $3 \times 3$ blocks, as

${ }^{23}$ This result is consistent with the tilt of the yield curve being driven by counter-cyclical monetary policy, as in Rudebusch and Wu (2003). 


$$
A=\left(\begin{array}{ll}
A_{1} & A_{2} \\
A_{3} & A_{4}
\end{array}\right),
$$

and similarly for the $6 \times 6 Q$ matrix,

$$
Q=\left(\begin{array}{ll}
Q_{1} & Q_{2} \\
Q_{2}^{T} & Q_{3}
\end{array}\right),
$$

where the superscript $T$ denotes transpose. We attribute all the covariance given by the block $Q_{2}$ to the effect of yield curve variables on the macro variables, as the latter come before the former in the recursive ordering we employ. As such, there are two links from yields to the macroeconomy in our setup: the contemporaneous link given by $Q_{2}$, and the effects of lagged yields on the macroeconomy embodied in $A_{2}$. Conversely, links from the macroeconomy to yields are embodied in $A_{3}$.

We report in Table 6 the results of likelihood ratio and Wald tests of several key restrictions on the $A$ and $Q$ matrices. Both tests overwhelmingly reject the "no interaction" hypothesis of $A_{2}=A_{3}=Q_{2}=0$. Interestingly, less severe restrictions allowing for unidirectional but not bidirectional links are similarly rejected. In particular, we reject both the hypothesis of "no macro to yields" link $\left(A_{2}=0\right)$ and the hypothesis of "no yields to macro" link $\left(A_{3}=Q_{2}=0\right)$. We conclude that there is clear statistical evidence in favor of a bidirectional link between the macroeconomy and the yield curve.

\section{$\underline{3.5 \text { Robustness to an Alternative Identification Strategy }}$}

Our results above are based on a recursive ordering of the variables. In this section we estimate a version of the macro-yields model with a diagonal $Q$ matrix. Imposition of the diagonality constraint allows us to sidestep issues of structural identification and highlight macro-finance linkages, without being tied to particular orderings or other identification schemes, which have been so contentious in the so-called "structural" VAR literature. In Table 7, we provide estimates of $A$ and the diagonal elements of $Q$, which are very close to those reported in Table 3 . Next we repeat the linkage tests and report the results in Table 8. Because we now maintain the assumption of diagonal $Q$ throughout, the hypotheses tested correspond to restrictions only on the $A$ matrix. Interestingly, we find considerably less evidence in favor of a yields to macro link than in the "non-diagonal $Q$ " case reported in Table 6: the Wald test statistic of the null hypothesis of no yields to macro link has a $p$-value of 0.19 .

We also compute the impulse responses for this version of the model. In Figure 6 we show both point and interval estimates of the impulse responses from the earlier-reported non-diagonal $Q$ version of the yields-macro model, along with the point estimates of the impulse responses from the diagonal $Q$ version for comparison. With only one or two exceptions out of 36 impulse response functions (the responses of capacity utilization and funds rate to a shock in slope), the differences are negligible. The 
same is of course also true for the variance decompositions, which we show for the diagonal $Q$ model in Table 9, and which are close to those reported earlier for the non-diagonal $Q$ version, with the possible exception of the significantly lower contribution of yield curve variables to the variation in the funds rate. This result is in line with the weak yield-to-macro linkage already documented for this version of the model.

\section{Examining The Expectations Hypothesis}

It is useful to contrast our representation of the yield curve with others that have appeared in the literature. Here we relate our yield curve modeling approach to the traditional macroeconomic approach based on the expectations hypothesis.

The expectations hypothesis of the term structure states that movements in long rates are due to movements in expected future short rates. Any term or risk premia are assumed to be constant through time. In terms of our notation above, which pertains to the pure discount bond yields in our data set, the theoretical bond yield consistent with the expectations hypothesis is

$$
y_{t}(\tau)^{E H} \equiv(1 / \tau) \sum_{i=0}^{\tau-1} E_{t} y_{t+i}(1)+c_{\tau}
$$

where $c$ is a term premium that may vary with the maturity $\tau$ but assumed to be constant through time.

The expectations hypothesis has long been a key building block in macroeconomics both in casual inference and formal modeling (see, for example, Fuhrer and Moore, 1995, or Rudebusch, 1995). However, various manifestations of the failure of the expectations hypothesis have been documented at least since Macaulay (1938). Campbell and Shiller (1991) and Fuhrer (1996) provide recent evidence on the failure of the expectations hypothesis, and we use their methodology to examine it in the context of

our model. Specifically, we compare the theoretical bond yields, $y_{t}(m)^{E H}$, constructed via (14) under the assumption that the expectations hypothesis holds, with the actual bond yields $y_{t}(m)$. We construct the expected future 1-month yields by iterating forward the estimated yields-macro model using equation ( $5^{\prime}$ ) and the measurement equation $\left(6^{\prime}\right)$ for $y_{t}(1)$, and then we compute the theoretical bond yields at each point in time using equation (14).

In Figure 7, we show for six maturities $(m=3,12,24,36,60,120)$ the theoretical yields implied by the expectations hypothesis, together with the actual yields. As in Fuhrer (1996), throughout our sample there are large deviations between the theoretical and actual yields, especially at longer 
maturities. ${ }^{24}$ Nevertheless, the actual and theoretical rates move together most of the time. Over the entire sample, for example, the correlation between the actual 10-year and 1-month yield spread, $\mathrm{y}_{t}(120)-y_{t}(1)$, and the theoretical spread, $y_{t}(120)^{E H}-y_{t}(1)$, is .60. Furthermore, during certain periods the actual and theoretical rates move very closely together. This partial success of the expectations hypothesis is consistent with Fuhrer (1996) and Kozicki and Tinsley (2001), who argue that much of the apparent failure of the expectations hypothesis reflects the assumption of a constant Fed reaction function - and in particular a constant inflation target - over the entire sample. Indeed, the expectations hypothesis fits much better during the second half of the sample, when inflation expectations were likely better anchored.

\section{Summary and Conclusions}

We have specified and estimated a yield curve model that incorporates both yield factors (level, slope, and curvature) and macroeconomic variables (real activity, inflation, and the stance of monetary policy). The model's convenient state-space representation facilitates estimation, the extraction of latent yield-curve factors, and testing of hypotheses regarding dynamic interactions between the macroeconomy and the yield curve. Interestingly, we find strong evidence of macroeconomic effects on the future yield curve and somewhat weaker evidence of yield curve effects on future macroeconomic developments. Hence, although bi-directional causality is likely present, effects in the tradition of Ang and Piazzesi (2003) seem relatively more important than those in the tradition of Estrella and Hardouvelis (1991), Estrella and Mishkin (1998), and Stock and Watson (2000). Of course, market yields do contain important predictive information about the Fed's policy rate. We also relate our yield curve modeling approach to a traditional macroeconomic approach based on the expectations hypothesis. The results indicate that the expectations hypothesis may hold reasonably well during certain periods, but that it does not hold across the entire sample.

From a finance perspective, our analysis is unusual in that we do not impose no-arbitrage restrictions. However, such an a priori restriction may in fact be violated in the data due to illiquidity in thinly-traded regions of the yield curve, so imposing it may be undesirable. Also, if the no-arbitrage restriction does indeed hold for the data, then it will at least approximately be captured by our fitted yield curves, because they are flexible approximations to the data. Nevertheless, in future work, we hope to derive the no-arbitrage condition in our framework and explore whether its imposition is helpful for forecasting, as suggested by Ang and Piazzesi (2003).

\footnotetext{
${ }^{24}$ Not surprisingly, a formal statistical test along the lines of Krippner (2002) rejects the restrictions placed by the expectations hypothesis on the yields-macro model.
} 


\section{Appendix}

\section{Calculation of Impulse Response Functions and Variance Decompositions}

In this appendix, we describe the computation of the impulse response functions (IRFs) and variance decompositions (VDs) for our models. All models in the paper can be written in VAR(1) form,

$$
y_{t}=\mu+A y_{t-1}+\varepsilon_{t}
$$

where $y_{t}$ is an $m \times 1$ vector of endogenous variables, $\mu$ is the constant vector and $A$ is the $m \times m$ transition matrix. The residuals $\varepsilon_{t}$ follow

$$
\varepsilon_{t} \sim N(0, \Omega)
$$

where $\Omega$ is a (potentially non-diagonal) variance-covariance matrix. In order to find the IRFs and VDs, we must write the VAR(1) in moving average (MA) form. Letting $I_{m}$ denote the $m \times m$ identity matrix, the unconditional mean of $y$ is $c=\left(I_{m}-A\right)^{-1} \mu$, and we can write the system as

$$
\left(y_{t}-c\right)=\mu+A\left(y_{t-1}-c\right)+\varepsilon_{t} .
$$

Assuming that $A$ satisfies the conditions for covariance stationarity, we can write the MA representation of the VAR as

$$
\left(y_{t}-c\right)=\psi_{0} \epsilon_{t}+\psi_{1} \epsilon_{t-1}+\psi_{2} \epsilon_{t-2}+\ldots=\sum_{i=0}^{\infty} \psi_{i} \varepsilon_{t-i}
$$

where $\psi_{0}=I_{m}$ and $\psi_{i}=A^{i}$ for $i=1,2, \ldots$

\section{A.1. Impulse-Response Functions}

We define the IRF of the system as the responses of the endogenous variables to one unit shocks in the residuals. One would often see responses to a "one standard deviation" shock instead of the "one unit" shock that we use. Because all the variables we use in our analysis are in percentage terms we find it more instructive to report results from one percentage point shocks to the residuals.

\section{A.1.1 Diagonal $\Omega$}

The response of $y_{t}^{i}$ to a one unit shock to $\varepsilon_{t-k}^{j}$ is

$$
\partial y_{t}^{i} / \partial \varepsilon_{t-k}^{j}=\left(\Psi_{k}\right)_{i j}
$$

where $\left(\psi_{k}\right)_{i j}$ is the $(i, j)$ element of the corresponding matrix. To compute the asymptotic standard errors of the IRFs, we follow Lütkepohl (1990). Let $\alpha=\operatorname{vec}(A)$ and $\sigma=\operatorname{vec}(\Omega)$. Suppose that

$$
\sqrt{T}\left[\begin{array}{l}
\hat{\alpha}-\alpha \\
\hat{\sigma}-\sigma
\end{array}\right]-N\left[\left(\begin{array}{l}
0 \\
0
\end{array}\right),\left(\begin{array}{cc}
\Sigma_{\alpha} & 0 \\
0 & \Sigma_{\sigma}
\end{array}\right)\right] .
$$

Then the asymptotic distribution of the IRFs can be derived using

$$
\sqrt{T} \operatorname{vec}\left(\psi_{k}-\Psi\right) \rightarrow N\left(0, G_{k} \Sigma_{\alpha} G_{k}^{\prime}\right),
$$

where 


\section{A.1.2 Non-Diagonal $\Omega$}

$$
G_{k}=\partial \operatorname{vec}\left(\Psi_{k}\right) / \partial \alpha^{\prime}=\sum_{i=0}^{k-1}\left(A^{\prime}\right)^{k-1-i} \otimes \Psi_{i} .
$$

When $\Omega$ is non-diagonal, we cannot compute the IRFs using the original residuals, $\varepsilon_{t}$. We use a Cholesky decomposition to obtain a lower-triangular matrix $P$ that satisfies $\Omega=P P^{\prime}$ to define $v_{t}=P^{-1} \varepsilon_{t}$. The transformed residuals have an identity covariance matrix, $E\left(v_{t} v_{t}^{\prime}\right)=P^{-1} \Omega P^{-1^{\prime}}=P^{-1} P P^{\prime} P^{-1^{\prime}}=I_{m}$. The response of $y_{t}$ to a one unit shock to $v_{t-k}^{j}$ is

$$
\partial y_{t} / \partial v_{t-k}^{j}=\psi_{k} p_{j} / \sqrt{\Omega_{j j}}
$$

where $p_{j}$ is the $j^{\text {th }}$ column of $P$ and $\Omega_{j j}$ is the $(j, j)$ element of the original variance covariance matrix.

To compute the asymptotic standard errors of the IRFs, assume that (A6) holds where now $\sigma=\operatorname{vech}(\Omega)$. Denote by $\Theta_{k}$ a matrix whose $(i, j)$ th element is the response of the $i^{\text {th }}$ variable in period $t$ to a one standard deviation shock to the $j^{\text {th }}$ variable in period $t-k$; that is, the $j^{\text {th }}$ column of $\Theta_{k}$ is given by $\Psi_{k} p_{j}$. Then the asymptotic distribution of $\Theta_{k}$ can be derived using

$$
\sqrt{T} \operatorname{vec}\left(\hat{\Theta}_{k}-\Theta\right) \rightarrow N\left(0, C_{k} \Sigma_{\alpha} C_{k}^{\prime}+\bar{C}_{k} \Sigma_{\sigma} \bar{C}_{k}^{\prime}\right),
$$

where

$$
\begin{aligned}
& C_{0}=0, \quad C_{k}=\left(P^{\prime} \otimes I_{m}\right) G_{k}, \quad k=1,2, \ldots \\
& \bar{C}_{k}=\left(I_{m} \otimes \Psi_{k}\right) H, \quad k=0,1,2 \ldots \\
& H=\partial \operatorname{vec}(P) / \partial \sigma^{\prime}=L_{m}^{\prime}\left\{L_{m}\left(I_{m^{2}}+K_{m m}\right)\left(P \otimes I_{m}\right) L_{m}^{\prime}\right\}^{-1},
\end{aligned}
$$

$L_{m}$ is a matrix such that $\operatorname{vech}(F)=L_{k} \operatorname{vec}(F), K_{m m}$ is a matrix such that $K_{m m} \operatorname{vec}(G)=\operatorname{vec}\left(G^{\prime}\right)$, and $G_{k}$ is as defined in (A8).

\section{A.2. Variance Decompositions}

The contribution of the $j^{\text {th }}$ variable to the mean squared error (MSE) of the $s$-period-ahead forecast, under the assumption of diagonal $\Omega$ is

$$
\operatorname{MSE}^{j}(s)=\operatorname{var}\left(\varepsilon_{t}^{j}\right)\left[I_{j} I_{j}^{\prime}+\Psi_{1} I_{j} I_{j}^{\prime} \psi_{1}^{\prime}+\ldots+\Psi_{s-1} I_{j} I_{j}^{\prime} \psi_{s-1}^{\prime}\right],
$$

while for the non-diagonal case it is

$$
\operatorname{MSE}^{j}(s)=\left[p_{j} p_{j}^{\prime}+\Psi_{1} p_{j} p_{j}^{\prime} \Psi_{1}^{\prime}+\ldots+\Psi_{s-1} p_{j} p_{j}^{\prime} \Psi_{s-1}^{\prime}\right]
$$

The MSE is given by

$$
\operatorname{MSE}(s)=\sum_{j=1}^{k} M S E^{j}(s)
$$

where both $M S E$ and $M S E^{j}$ are $m \times m$ matrices. We define the VD at horizon $s$ as the fraction of MSE of the $i^{\text {th }}$ variable due to shocks to the $j^{\text {th }}$ variable:

$$
V D C_{i}^{j}(s)=M S E_{i i}^{j}(s) / M S E_{i i}(s),
$$

where $M S E_{i i}$ and $M S E_{i i}^{j}(s)$ denote the $(i, i)$ elements of the respective matrices.

To compute the VD of the yields, we combine the result above with the measurement equation for the yields, 


$$
m_{\tau}=\beta_{1}+\alpha(\tau) \beta_{2}+\gamma(\tau) \beta_{3}
$$

where $\alpha(\tau)$ and $\gamma(\tau)$ follow from equation (1). The contribution of the $j^{\text {th }}$ variable to the MSE of the $s$ period ahead forecast of the yield at maturity $\tau$ is given by

$$
\begin{aligned}
M \tilde{S} E^{j}(s, \tau)= & M S E_{11}^{j}(s)+\alpha(\tau)^{2} M S E_{22}^{j}(s)+\gamma(\tau)^{2} M S E_{33}^{j}(s) \\
& +2 \alpha(\tau) M S E_{12}^{j}(s)+2 \gamma(\tau) M S E_{13}^{j}(s)+2 \alpha(\tau) \gamma(\tau) M S E_{23}^{j}(s),
\end{aligned}
$$

where we assume that the factors $\beta_{1}, \beta_{2}$ and $\beta_{3}$ are the first three elements of the vector $y$. Similarly, the MSE of the $s$-period ahead forecast of the yield at maturity $\tau$ is given by

$$
M \tilde{S} E(s, \tau)=\sum_{j=1}^{k} M \tilde{S} E^{j}(s, \tau)
$$

and the VD of the yield with maturity $\tau$ is the MSE of the yield due to the $\mathrm{j}^{\text {th }}$ variable at horizon $s$ :

$$
V \tilde{D} C_{i}^{j}(s, \tau)=M \tilde{S} E_{i i}^{j}(s, \tau) / M \tilde{S} E_{i i}(s, \tau) .
$$




\section{References}

Ang, A. and Piazzesi, M. (2003), “A No-Arbitrage Vector Autoregression of Term Structure Dynamics with Macroeconomic and Latent Variables," Journal of Monetary Economics, 50, 745-787.

Ang, A., Piazzesi, M. And Wei, M. (2003), "What Does the Yield Curve Tell us About GDP Growth?," manuscript, Columbia University and UCLA.

Bank for International Settlements (1999), “Zero-Coupon Yield Curves: Technical Documentation,” Bank for International Settlements, Switzerland.

Björk, T. and Christensen, B. (1999), "Interest Rate Dynamics and Consistent Forward Rate Curves," Mathematical Finance, 9, 323-348.

Brousseau, V. (2002), “The Functional Form of Yield Curves,” Working Paper 148, European Central Bank.

Campbell, J.Y. and R.J. Shiller (1991), "Yield Spreads and Interest Rate Movements: A Bird's Eye View," Review of Economic Studies, 57, 495-514.

Dahlquist M. and L.E.O. Svensson (1996), "Estimating the Term Structure of Interest Rates for Monetary Policy Analysis," Scandinavian Journal of Economics, 98, 163-183.

Dai Q. and Singleton, K. (2000), "Specification Analysis of Affine Term Structure Models," Journal of Finance, 55, 1943-1978.

Dewachter, H. and Lyrio, M. (2002), "Macroeconomic Factors in the Term Structure of Interest Rates," Manuscript, Catholic University Leuven and Erasmus University Rotterdam.

Diebold, F.X. and Li., C. (2002), "Forecasting the Term Structure of Government Bond Yields," Manuscript, Department of Economics, University of Pennsylvania.

Duffee, G. (2002), "Term Premia and Interest Rate Forecasts in Affine Models," Journal of Finance, 57, 405-443.

Duffie, D. and Kan, R. (1996), “A Yield-Factor Model of Interest Rates,” Mathematical Finance, 6, 379-406.

Durbin, J. and S.J. Koopman (2001), Time Series Analysis by State Space Methods. Oxford: Oxford University Press..

Estrella, A. and Hardouvelis, G.A. (1991), "The Term Structure as a Predictor of Real Economic Activity," Journal of Finance, 46, 555-576.

Estrella, A. and Mishkin, F.S. (1998), "Predicting U.S. Recessions: Financial Variables as Leading Indicators," Review of Economics and Statistics, 80, 45-61.

Evans, C.L. and Marshall, D. (1998), "Monetary Policy and the Term Structure of Nominal Interest Rates: Evidence and Theory," Carnegie-Rochester Conference Series on Public Policy, 49, 53- 
111.

Evans, C.L. and Marshall, D. (2001), "Economic Determinants of the Nominal Treasury Yield Curve," Manuscript, Federal Reserve Bank of Chicago.

Fama, E. and Bliss, R. (1987), “The Information in Long-Maturity Forward Rates," American Economic Review, 77, 680-692.

Fuhrer, J. (1996), "Monetary Policy Shifts and Long-Term Interest Rates," The Quarterly Journal of Economics, 1183-1209.

Fuhrer, J., and G. Moore (1995), "Monetary Policy Trade-Offs and the Correlation Between Nominal Interest Rates and Real Output," American Economic Review 85, 219-239.

Gurkaynak, R.S., Sack, B., and Swanson E. (2003), "The Excess Sensitivity of Long-Term Interest Rates: Evidence and Implications for Macroeconomic Models," Manuscript, Federal Reserve Board.

Harvey, A.C. (1981), Time Series Models (Second Edition, 1993). Cambridge: MIT Press.

Hördahl, P., Tristani, O. and Vestin, D. (2002), “A Joint Econometric Model of Macroeconomic and Term Structure Dynamics,” Manuscript, European Central Bank.

Knez, P., Litterman, R. and Scheinkman, J. (1994), "Exploration into Factors Explaining Money Market Returns," Journal of Finance, 49, 1861-1882.

Kozicki, S. and Tinsley, P.A. (2001), "Shifting Endpoints in the Term Structure of Interest Rates," Journal of Monetary Economics, 47, 613-652.

Krippner, L. (2002), “The OLP Model of the Yield Curve: A New Consistent Cross-sectional and Intertemporal Approach," manuscript, Victoria University of Wellington.

Lütkepohl, H. (1990), “Asymptotic Distributions of Impulse Response Functions and Forecast Error Variance Decompositions of Vector Autoregressive Models," Review of Economics and Statistics, 72, 116-125.

Macaulay, F.R. (1938), Some Theoretical Problems Suggested by the Movements of Interest Rates, Bond Yields, and Stock Prices in the United States Since 1856, (New York: NBER).

Nelson, C.R. and Siegel, A.F. (1987), "Parsimonious Modeling of Yield Curves," Journal of Business, 60, 473-489.

Rudebusch, G.D. (1995), "Federal Reserve Interest Rate Targeting, Rational Expectations, and the Term Structure," Journal of Monetary Economics 35, 245-274.

Rudebusch, G.D. (1998), “Do Measures of Monetary Policy in a VAR Make Sense?,” International Economic Review 39, 907-931.

Rudebusch, G.D. (2002), “Term Structure Evidence on Interest Rate Smoothing and Monetary Policy Inertia," Journal of Monetary Economics 49, 1161-1187. 
Rudebusch, G.D. and Svensson, L.E.O. (1999), "Policy Rules for Inflation Targeting," in J.B. Taylor (ed.), Monetary Policy Rules. Chicago: University of Chicago Press, 203-246.

Rudebusch, G.D. and Wu, T. (2003), “A Macro-Finance Model of the Term Structure, Monetary Policy, and the Economy," Manuscript, Federal Reserve Bank of San Francisco.

Stock, J.H. and Watson, M.W. (2000), "Forecasting Output and Inflation: The Role of Asset Prices," Manuscript, Kennedy School of Government, Revised January 2003.

Wu, T. (2002), "Monetary Policy and the Slope Factors in Empirical Term Structure Estimations," Federal Reserve Bank of San Francisco Working Paper 02-07. 
Table 1

Yields-Only Model Parameter Estimates

\begin{tabular}{cccc|c}
\hline \hline & $L_{t-1}$ & $S_{t-1}$ & $C_{t-1}$ & $\mu$ \\
\hline \multirow{2}{*}{$L_{t}$} & $\mathbf{0 . 9 9}$ & $\mathbf{0 . 0 3}$ & -0.02 & $\mathbf{8 . 0 2}$ \\
& $(0.01)$ & $(0.01)$ & $(0.01)$ & $(1.67)$ \\
\multirow{2}{*}{$S_{t}$} & -0.03 & $\mathbf{0 . 9 4}$ & 0.04 & $\mathbf{- 1 . 4 4}$ \\
& $(0.02)$ & $(0.02)$ & $(0.03)$ & $(0.60)$ \\
& & & & -0.42 \\
$C_{t}$ & 0.03 & 0.02 & $\mathbf{0 . 8 4}$ & $(0.54)$ \\
\hline
\end{tabular}

Notes: Each row presents coefficients from the transition equation for the respective state variable. Bold entries denote parameter estimates significant at the 5 percent level. Standard errors appear in parentheses.

\section{Estimated $Q$ Matrix}

\begin{tabular}{cccc}
\hline \hline & $L_{t}$ & $S_{t}$ & $C_{t}$ \\
\hline$L_{t}$ & $\mathbf{0 . 0 9}$ & -0.01 & $\mathbf{0 . 0 4}$ \\
& $(0.01)$ & $(0.01)$ & $(0.02)$ \\
$S_{t}$ & & & \\
& & $\mathbf{0 . 3 8}$ & 0.01 \\
& & $(0.03)$ & $(0.03)$ \\
$C_{t}$ & & & \\
& & & $\mathbf{0 . 8 0}$ \\
\hline
\end{tabular}

Notes: Bold entries denote parameter estimates significant at the 5 percent level. Standard errors appear in parentheses.

\section{Tests for Diagonality of $Q$ Matrix}

\begin{tabular}{lcc}
\hline \hline & Test Statistic & P-Value \\
\hline Likelihood Ratio & 6.75 & 0.08 \\
Wald & 7.65 & 0.05 \\
\hline
\end{tabular}

Note: Both test statistics are Chi-square with 3 degrees of freedom. 


\section{Table 2}

\section{Summary Statistics for Measurement Errors of Yields}

\begin{tabular}{ccccc}
\hline \hline & \multicolumn{2}{c}{ Yields-Only Model } & \multicolumn{2}{c}{ Yields-Macro Model } \\
Maturity & Mean & Standard Deviation & Mean & Standard Deviation \\
\hline 3 & -12.64 & 22.36 & -12.53 & 22.21 \\
6 & -1.34 & 5.07 & -1.26 & 4.84 \\
9 & 0.49 & 8.11 & 0.54 & 8.15 \\
12 & 1.31 & 9.87 & 1.33 & 9.88 \\
15 & 3.71 & 8.71 & 3.72 & 8.76 \\
18 & 3.59 & 7.29 & 3.58 & 7.31 \\
21 & 3.23 & 6.51 & 3.22 & 6.47 \\
24 & -1.40 & 6.39 & -1.42 & 6.35 \\
30 & -2.65 & 6.06 & -2.68 & 6.08 \\
36 & -3.24 & 6.59 & -3.27 & 6.61 \\
48 & -1.85 & 9.70 & -1.87 & 9.73 \\
60 & -3.29 & 8.03 & -3.29 & 8.01 \\
72 & 1.97 & 9.14 & 1.99 & 9.11 \\
84 & 0.69 & 10.37 & 0.72 & 10.38 \\
96 & 3.49 & 9.04 & 3.53 & 9.16 \\
108 & 4.19 & 13.64 & 4.25 & 13.74 \\
120 & -1.31 & 16.45 & -1.25 & 16.57 \\
\hline
\end{tabular}

Notes: We report the means and standard deviations of the measurement errors, expressed in basis points, for yields of various maturities measured in months. 
Table 3

Yields-Macro Model Parameter Estimates

\begin{tabular}{lcccccc|c}
\hline \hline & $L_{t-1}$ & $S_{t-1}$ & $C_{t-1}$ & $C U_{t-1}$ & $F F R_{t-1}$ & $I N F L_{t-1}$ & $\mu$ \\
\hline$L_{t}$ & $\mathbf{0 . 9 0}$ & $\mathbf{- 0 . 0 6}$ & -0.02 & -0.01 & $\mathbf{0 . 0 8}$ & 0.01 & $\mathbf{7 . 5 6}$ \\
& $(0.04)$ & $(0.04)$ & $(0.01)$ & $(0.01)$ & $(0.04)$ & $(0.01)$ & $(1.75)$ \\
$S_{t}$ & $\mathbf{- 0 . 4 3}$ & $\mathbf{0 . 4 8}$ & 0.03 & $\mathbf{0 . 0 3}$ & $\mathbf{0 . 3 8}$ & 0.03 & $\mathbf{- 1 . 5 3}$ \\
& $(0.07)$ & $(0.07)$ & $(0.04)$ & $(0.02)$ & $(0.06)$ & $(0.03)$ & $(0.49)$ \\
$C_{t}$ & 0.14 & 0.12 & $\mathbf{0 . 8 4}$ & 0.01 & -0.09 & 0.00 & -0.49 \\
& $(0.12)$ & $(0.12)$ & $(0.04)$ & $(0.02)$ & $(0.10)$ & $(0.04)$ & $(0.59)$ \\
$C U_{t}$ & 0.07 & -0.02 & 0.00 & $\mathbf{1 . 0 0}$ & -0.07 & -0.02 & $\mathbf{8 0 . 7 3}$ \\
& $(0.08)$ & $(0.08)$ & $(0.04)$ & $(0.02)$ & $(0.07)$ & $(0.02)$ & $(0.79)$ \\
$F F R_{t}$ & 0.00 & -0.09 & 0.01 & $\mathbf{0 . 0 5}$ & $\mathbf{0 . 9 9}$ & 0.05 & $\mathbf{6 . 5 3}$ \\
& $(0.09)$ & $(0.09)$ & $(0.03)$ & $(0.03)$ & $(0.07)$ & $(0.04)$ & $(2.06)$ \\
& & & & & & & \\
& & & & & & & \\
& -0.04 & -0.04 & -0.01 & $\mathbf{0 . 0 3}$ & 0.04 & $\mathbf{0 . 9 9}$ & $\mathbf{4 . 1 8}$ \\
& $(0.04)$ & $(0.04)$ & $(0.01)$ & $(0.00)$ & $(0.03)$ & $(0.01)$ & $(1.13)$ \\
\hline
\end{tabular}

Notes: Each row presents coefficients from the transition equation for the respective state variable. Bold entries denote parameter estimates significant at the 5 percent level. Standard errors appear in parentheses.

Estimated $Q$ Matrix

\begin{tabular}{lcccccc}
\hline \hline & $L_{t}$ & $S_{t}$ & $C_{t}$ & $C U_{t}$ & $F F R_{t}$ & $I N F L_{t}$ \\
\hline$L_{t}$ & $\mathbf{0 . 0 9}$ & -0.02 & 0.05 & $\mathbf{0 . 0 4}$ & 0.03 & $\mathbf{0 . 0 1}$ \\
& $(0.01)$ & $(0.02)$ & $(0.03)$ & $(0.02)$ & $(0.02)$ & $(0.00)$ \\
$S_{t}$ & & $\mathbf{0 . 3 0}$ & 0.01 & $\mathbf{0 . 0 8}$ & $\mathbf{0 . 2 2}$ & -0.01 \\
& & $(0.03)$ & $(0.04)$ & $(0.02)$ & $(0.03)$ & $(0.01)$ \\
$C_{t}$ & & & $\mathbf{0 . 8 1}$ & 0.04 & $\mathbf{0 . 1 7}$ & 0.00 \\
& & & $(0.09)$ & $(0.04)$ & $(0.04)$ & $(0.01)$ \\
$C U_{t}$ & & & & $\mathbf{0 . 3 7}$ & $\mathbf{0 . 1 5}$ & $\mathbf{0 . 0 2}$ \\
& & & & $(0.03)$ & $(0.04)$ & $(0.01)$ \\
$F F R_{t}$ & & & & & $\mathbf{0 . 4 5}$ & 0.00 \\
& & & & & $(0.03)$ & $(0.01)$ \\
$I N F L_{t}$ & & & & & & $\mathbf{0 . 0 5}$ \\
& & & & & & $(0.00)$ \\
\hline
\end{tabular}

Notes: Bold entries denote parameter estimates significant at the 5 percent level. Standard errors appear in parentheses.

Tests for Diagonality of $Q$ Matrix

\begin{tabular}{lcc}
\hline \hline & Test Statistic & P-Value \\
\hline Likelihood Ratio & 307.89 & 0.00 \\
Wald & 209.21 & 0.00 \\
\hline Note: Both test statistics are Chi-square with & 15 degrees of \\
freedom. &
\end{tabular}




\section{Table 4}

Variance Decompositions, Yields

\begin{tabular}{|c|c|c|c|c|c|c|c|}
\hline & "Horizon & $\bar{L}$ & $\bar{S}$ & $\bar{C}$ & $\overline{C U}$ & $\overline{F F R}$ & $\overline{I N F L}$ \\
\hline \multicolumn{8}{|c|}{ 1-Month Yield } \\
\hline \multirow{3}{*}{$\begin{array}{l}\text { Yields-Only } \\
\text { Model }\end{array}$} & 1 & 0.17 & 0.83 & 0.00 & -- & -- & -- \\
\hline & 12 & 0.17 & 0.82 & 0.01 & -- & -- & -- \\
\hline & 60 & 0.17 & 0.82 & 0.02 & -- & -- & -- \\
\hline \multirow{3}{*}{$\begin{array}{c}\text { Yields-Macro } \\
\text { Model }\end{array}$} & 1 & 0.15 & 0.75 & 0.02 & 0.01 & 0.07 & 0.00 \\
\hline & 12 & 0.19 & 0.34 & 0.04 & 0.15 & 0.28 & 0.01 \\
\hline & 60 & 0.34 & 0.13 & 0.09 & 0.31 & 0.12 & 0.02 \\
\hline \multicolumn{8}{|c|}{ 12-Month Yield } \\
\hline \multirow{3}{*}{$\begin{array}{l}\text { Yields-Only } \\
\text { Model }\end{array}$} & 1 & 0.31 & 0.54 & 0.15 & -- & -- & -- \\
\hline & 12 & 0.31 & 0.62 & 0.07 & -- & -- & -- \\
\hline & 60 & 0.28 & 0.68 & 0.04 & -- & -- & -- \\
\hline \multirow{3}{*}{$\begin{array}{c}\text { Yields-Macro } \\
\text { Model }\end{array}$} & 1 & 0.30 & 0.44 & 0.22 & 0.00 & 0.04 & 0.00 \\
\hline & 12 & 0.33 & 0.22 & 0.13 & 0.11 & 0.21 & 0.01 \\
\hline & 60 & 0.41 & 0.08 & 0.12 & 0.28 & 0.09 & 0.03 \\
\hline \multicolumn{8}{|c|}{ 60-Month Yield } \\
\hline \multirow{3}{*}{$\begin{array}{l}\text { Yields-Only } \\
\text { Model }\end{array}$} & 1 & 0.69 & 0.13 & 0.17 & -- & -- & -- \\
\hline & 12 & 0.67 & 0.28 & 0.05 & -- & -- & -- \\
\hline & 60 & 0.51 & 0.48 & 0.02 & -- & -- & -- \\
\hline \multirow{3}{*}{$\begin{array}{c}\text { Yields-Macro } \\
\text { Model }\end{array}$} & 1 & 0.68 & 0.09 & 0.21 & 0.00 & 0.02 & 0.00 \\
\hline & 12 & 0.66 & 0.06 & 0.08 & 0.04 & 0.15 & 0.01 \\
\hline & 60 & 0.52 & 0.02 & 0.10 & 0.24 & 0.08 & 0.04 \\
\hline
\end{tabular}

Notes: Each entry is the proportion of the forecast variance (at the specified forecast horizon) for a 1-, 12- or 60-month yield that is explained by the particular factor. 


\section{Table 5}

Variance Decompositions, Macroeconomic Variables

\begin{tabular}{|c|c|c|c|c|c|c|c|}
\hline & "Horizon & $\bar{L}$ & $\bar{S}$ & $\overline{C C}$ & $\overline{C C U}$ & $\overline{F F F R}$ & $\overline{I N N F L}$ \\
\hline \multicolumn{8}{|c|}{$\underline{\mathbf{C U}}$} \\
\hline \multirow{3}{*}{$\begin{array}{c}\text { Macro-Only } \\
\text { Model }\end{array}$} & 1 & -- & -- & -- & 1.00 & 0.00 & 0.00 \\
\hline & 12 & -- & -- & -- & 0.89 & 0.10 & 0.01 \\
\hline & 60 & -- & -- & -- & 0.61 & 0.27 & 0.12 \\
\hline \multirow{3}{*}{$\begin{array}{c}\text { Yields-Macro } \\
\text { Model }\end{array}$} & 1 & 0.05 & 0.06 & 0.00 & 0.89 & 0.00 & 0.00 \\
\hline & 12 & 0.10 & 0.03 & 0.02 & 0.73 & 0.12 & 0.01 \\
\hline & 60 & 0.12 & 0.05 & 0.05 & 0.50 & 0.18 & 0.10 \\
\hline \multicolumn{8}{|c|}{$\underline{\text { FFR }}$} \\
\hline \multirow{3}{*}{$\begin{array}{c}\text { Macro-Only } \\
\text { Model }\end{array}$} & 1 & -- & -- & -- & 0.00 & 1.00 & 0.00 \\
\hline & 12 & -- & -- & -- & 0.04 & 0.95 & 0.01 \\
\hline & 60 & -- & -- & -- & 0.34 & 0.64 & 0.02 \\
\hline \multirow{3}{*}{$\begin{array}{c}\text { Yields-Macro } \\
\text { Model }\end{array}$} & 1 & 0.03 & 0.37 & 0.06 & 0.04 & 0.50 & 0.00 \\
\hline & 12 & 0.16 & 0.23 & 0.04 & 0.17 & 0.39 & 0.01 \\
\hline & 60 & 0.32 & 0.10 & 0.09 & 0.31 & 0.16 & 0.02 \\
\hline \multicolumn{8}{|c|}{$\underline{\text { INFL }}$} \\
\hline \multirow{3}{*}{$\begin{array}{c}\text { Macro-Only } \\
\text { Model }\end{array}$} & 1 & -- & -- & -- & 0.00 & 0.00 & 1.00 \\
\hline & 12 & -- & -- & -- & 0.21 & 0.00 & 0.78 \\
\hline & 60 & -- & -- & -- & 0.53 & 0.26 & 0.21 \\
\hline \multirow{3}{*}{$\begin{array}{c}\text { Yields-Macro } \\
\text { Model }\end{array}$} & 1 & 0.02 & 0.00 & 0.00 & 0.04 & 0.00 & 0.94 \\
\hline & 12 & 0.04 & 0.00 & 0.03 & 0.29 & 0.01 & 0.63 \\
\hline & 60 & 0.09 & 0.05 & 0.12 & 0.44 & 0.11 & 0.20 \\
\hline
\end{tabular}

Notes: Each entry is the proportion of the forecast variance (at the specified forecast horizon) for capacity utilization, funds rate and inflation that is explained by the particular factor. 


\section{Table 6}

\section{Tests of Macro-Yield Interactions}

\begin{tabular}{lccc}
\hline \hline & No Interaction & No Macro to Yields & No Yields to Macro \\
& $\boldsymbol{A 2}=\mathbf{0}, \boldsymbol{A 3}=\mathbf{0}$ and $\mathbf{Q 2}=\mathbf{0}$ & $\boldsymbol{A 2}=\mathbf{0}$ & $\boldsymbol{A 3}=\mathbf{0}$ and $\boldsymbol{Q 2}=\mathbf{0}$ \\
\hline Number of Restrictions & 27 & 9 & 18 \\
Likelihood Ratio Statistic & 362.11 & 107.13 & 258.66 \\
& $(0.00)$ & $(0.00)$ & $(0.00)$ \\
Wald Statistic & 452.41 & & \\
& $(0.00)$ & 93.78 & 345.76 \\
& & $(0.00)$ & $(0.00)$ \\
\hline
\end{tabular}

Notes: $p$-values appear in parentheses. $A 2, A 3$ and $Q 2$ refers to the relevant blocks of $A$ and $Q$ matrices as explained in the text. All test statistics in each column is a Chi-squared with the degrees of freedom equal to the number of restrictions. 
Table 7

Parameter Estimates, Yields-Macro Model, Diagonal $Q$

\begin{tabular}{lcccccc|c|c}
\hline \hline & $L_{t-1}$ & $S_{t-1}$ & $C_{t-1}$ & $C U_{t-1}$ & $F F R_{t-1}$ & $I N F L_{t-1}$ & $\mu$ & $Q_{i i}$ \\
\hline$L_{t}$ & $\mathbf{0 . 8 9}$ & $\mathbf{- 0 . 0 7}$ & -0.02 & -0.01 & $\mathbf{0 . 0 8}$ & 0.02 & $\mathbf{7 . 6 0}$ & $\mathbf{0 . 0 9}$ \\
& $(0.03)$ & $(0.04)$ & $(0.02)$ & $(0.01)$ & $(0.03)$ & $(0.02)$ & $(1.13)$ & $(0.01)$ \\
$S_{t}$ & $\mathbf{- 0 . 4 1}$ & $\mathbf{0 . 5 0}$ & 0.03 & $\mathbf{0 . 0 3}$ & $\mathbf{0 . 3 6}$ & 0.03 & $\mathbf{- 1 . 4 8}$ & $\mathbf{0 . 3 0}$ \\
& $(0.07)$ & $(0.07)$ & $(0.04)$ & $(0.01)$ & $(0.06)$ & $(0.03)$ & $(0.35)$ & $(0.03)$ \\
$C_{t}$ & 0.17 & 0.15 & $\mathbf{0 . 8 4}$ & 0.01 & -0.12 & 0.00 & -0.43 & $\mathbf{0 . 8 4}$ \\
& $(0.12)$ & $(0.12)$ & $(0.04)$ & $(0.02)$ & $(0.10)$ & $(0.04)$ & $(0.61)$ & $(0.08)$ \\
$C U_{t}$ & 0.09 & 0.00 & 0.00 & $\mathbf{1 . 0 0}$ & -0.08 & -0.02 & $\mathbf{8 0 . 7 2}$ & $\mathbf{0 . 3 7}$ \\
& $(0.08)$ & $(0.08)$ & $(0.03)$ & $(0.01)$ & $(0.07)$ & $(0.02)$ & $(1.17)$ & $(0.03)$ \\
$F F R_{t}$ & 0.02 & -0.06 & 0.02 & $\mathbf{0 . 0 5}$ & $\mathbf{0 . 9 7}$ & 0.05 & $\mathbf{6 . 6 1}$ & $\mathbf{0 . 4 2}$ \\
& $(0.08)$ & $(0.09)$ & $(0.03)$ & $(0.02)$ & $(0.06)$ & $(0.05)$ & $(1.30)$ & $(0.03)$ \\
& & & & & & & & \\
& & & & & & & & \\
& -0.04 & -0.03 & -0.01 & $\mathbf{0 . 0 3}$ & 0.04 & $\mathbf{0 . 9 9}$ & $\mathbf{4 . 2 8}$ & $\mathbf{0 . 0 5}$ \\
& $(0.03)$ & $(0.03)$ & $(0.01)$ & $(0.00)$ & $(0.02)$ & $(0.01)$ & $(1.43)$ & $(0.00)$ \\
\hline
\end{tabular}

Notes: Each row represents the transition equation for the respective state variable. Bold entries denote parameter estimates significant at the 5 percent level. Standard errors appear in parentheses. 


\section{Table 8 \\ Tests of Transition Matrix Restrictions, Diagonal $Q$}

\begin{tabular}{lccc}
\hline \hline & $\begin{array}{c}\text { No Interaction } \\
\boldsymbol{A 2}=\boldsymbol{0} \text { and } \boldsymbol{A 3}=\boldsymbol{0}\end{array}$ & $\begin{array}{c}\text { No Macro to Yields } \\
\boldsymbol{A 2}=\boldsymbol{0}\end{array}$ & $\begin{array}{c}\text { No Yields to Macro } \\
\boldsymbol{A 3}=\boldsymbol{0}\end{array}$ \\
\hline LR & 123.81 & 101.94 & 24.85 \\
& $(0.00)$ & $(0.00)$ & $(0.00)$ \\
Wald & 249.23 & 115.34 & 12.50 \\
& $(0.00)$ & $(0.00)$ & $(0.19)$ \\
\hline
\end{tabular}

Notes: $p$-values appear in parentheses. 
Table 9

Variance Decompositions, Yields-Macro Model, Diagonal $Q$

\begin{tabular}{|c|c|c|c|c|c|c|}
\hline Horizon & $L$ & $S$ & $C$ & $C U$ & FFR & INFL \\
\hline \multicolumn{7}{|c|}{ 1-Month Yield } \\
\hline 1 & 0.23 & 0.62 & 0.00 & 0.00 & 0.14 & 0.00 \\
\hline 12 & 0.11 & 0.16 & 0.00 & 0.09 & 0.63 & 0.01 \\
\hline 60 & 0.23 & 0.08 & 0.07 & 0.35 & 0.24 & 0.03 \\
\hline \multicolumn{7}{|c|}{ 12-Month Yield } \\
\hline 1 & 0.33 & 0.37 & 0.22 & 0.00 & 0.08 & 0.00 \\
\hline 12 & 0.23 & 0.11 & 0.10 & 0.07 & 0.49 & 0.01 \\
\hline 60 & 0.29 & 0.07 & 0.11 & 0.31 & 0.18 & 0.04 \\
\hline \multicolumn{7}{|c|}{ 60-Month Yield } \\
\hline 1 & 0.67 & 0.06 & 0.23 & 0.00 & 0.03 & 0.00 \\
\hline 12 & 0.54 & 0.05 & 0.08 & 0.01 & 0.31 & 0.01 \\
\hline 60 & 0.37 & 0.07 & 0.11 & 0.25 & 0.15 & 0.06 \\
\hline \multicolumn{7}{|c|}{$\underline{\mathbf{C U}}$} \\
\hline 1 & 0.00 & 0.00 & 0.00 & 1.00 & 0.00 & 0.00 \\
\hline 12 & 0.03 & 0.00 & 0.00 & 0.78 & 0.17 & 0.00 \\
\hline 60 & 0.05 & 0.01 & 0.02 & 0.55 & 0.28 & 0.08 \\
\hline \multicolumn{7}{|c|}{ FFR } \\
\hline 1 & 0.00 & 0.00 & $\overline{0.00}$ & 0.00 & 1.00 & 0.00 \\
\hline 12 & 0.04 & 0.01 & 0.00 & 0.10 & 0.83 & 0.01 \\
\hline 60 & 0.20 & 0.04 & 0.07 & 0.34 & 0.33 & 0.02 \\
\hline \multicolumn{7}{|c|}{ INFL } \\
\hline 1 & 0.00 & 0.00 & $\overline{0.00}$ & 0.00 & 0.01 & 0.98 \\
\hline 12 & 0.00 & 0.03 & 0.04 & 0.20 & 0.03 & 0.70 \\
\hline 60 & 0.03 & 0.02 & 0.08 & 0.48 & 0.19 & 0.20 \\
\hline
\end{tabular}

Notes: Each entry is the proportion of the forecast variance (at the specified forecast horizon) for a 1-, 12- or 60-month yield and capacity utilization, funds rate and inflation that is explained by the particular factor. 
Figure 1

Estimates of Level, Slope, and Curvature in Yields-Only Model

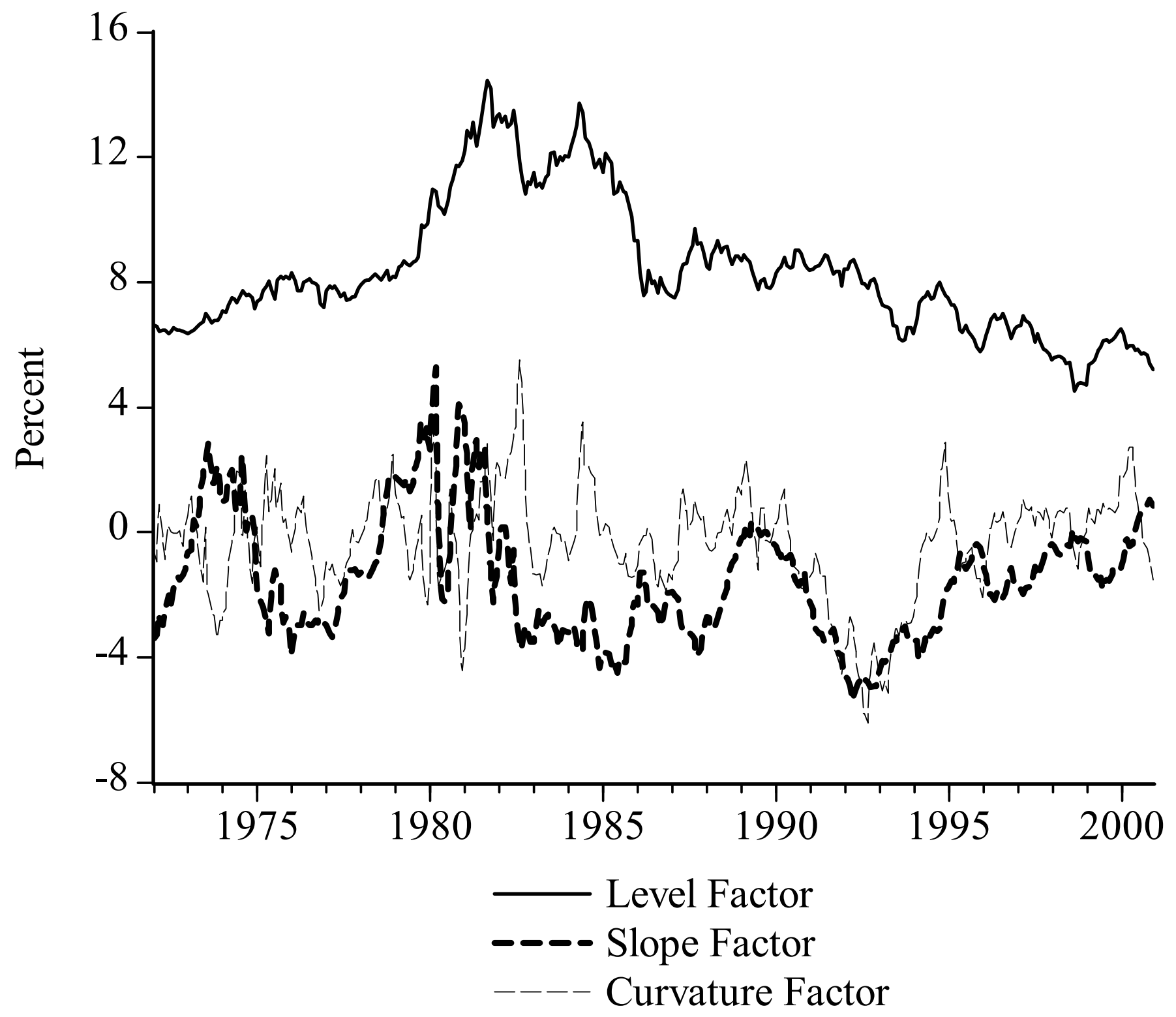


Figure 2

Yields-Only Model Level Factor and Empirical Counterparts

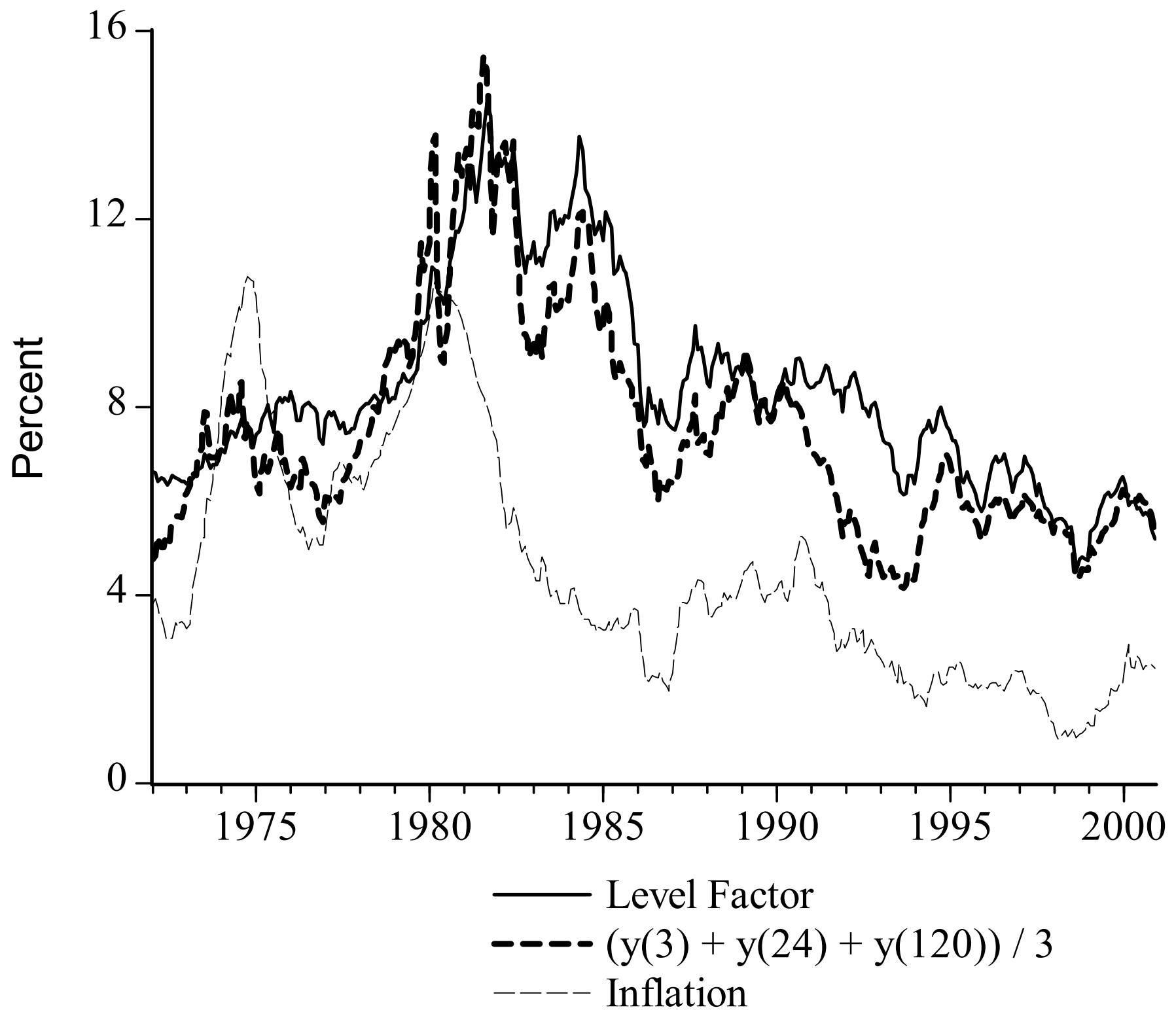


Figure 3

Yields-Only Model Slope Factor and Empirical Counterparts

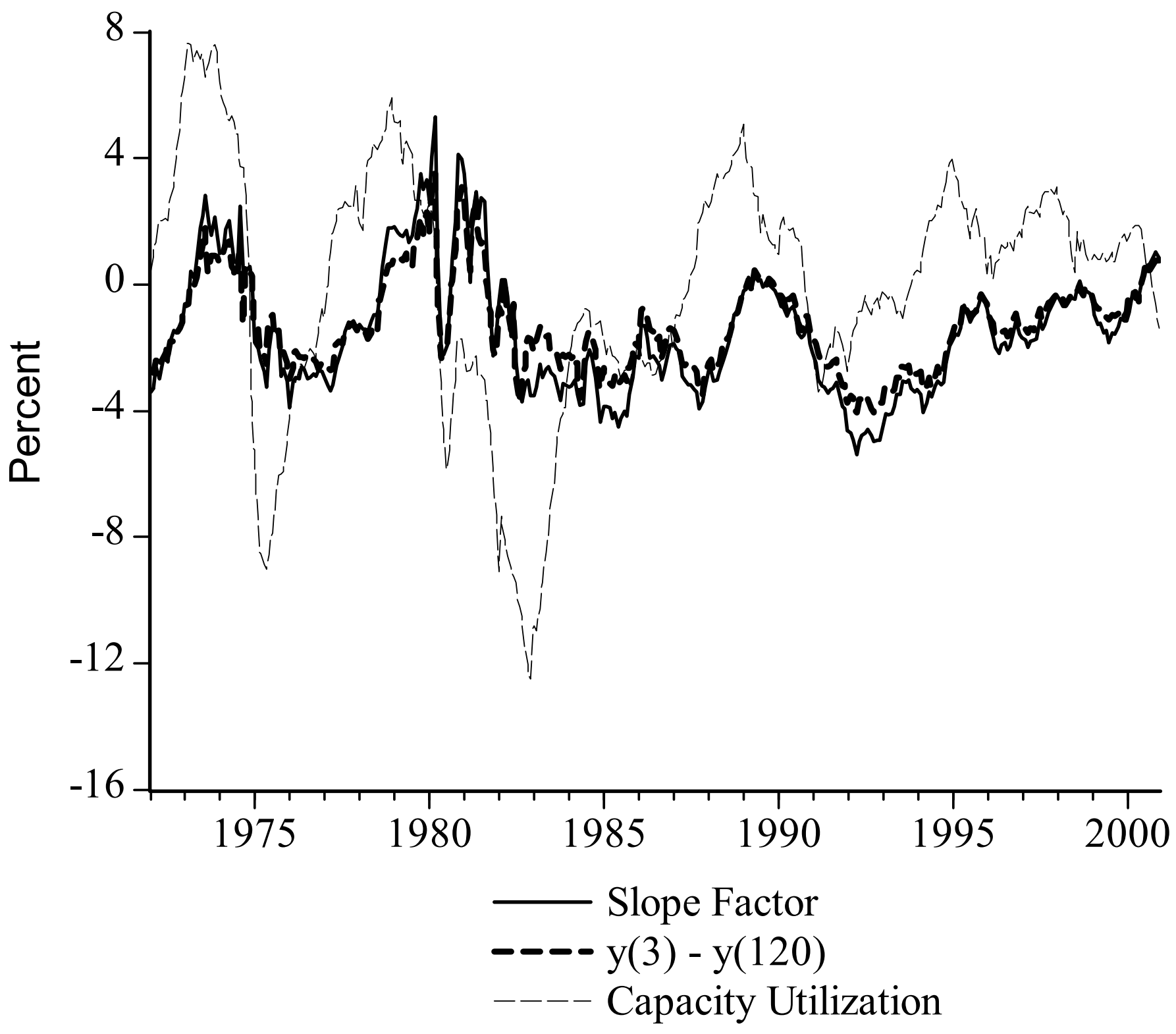


Figure 4

Yields-Only Model Curvature Factor and Empirical Counterpart

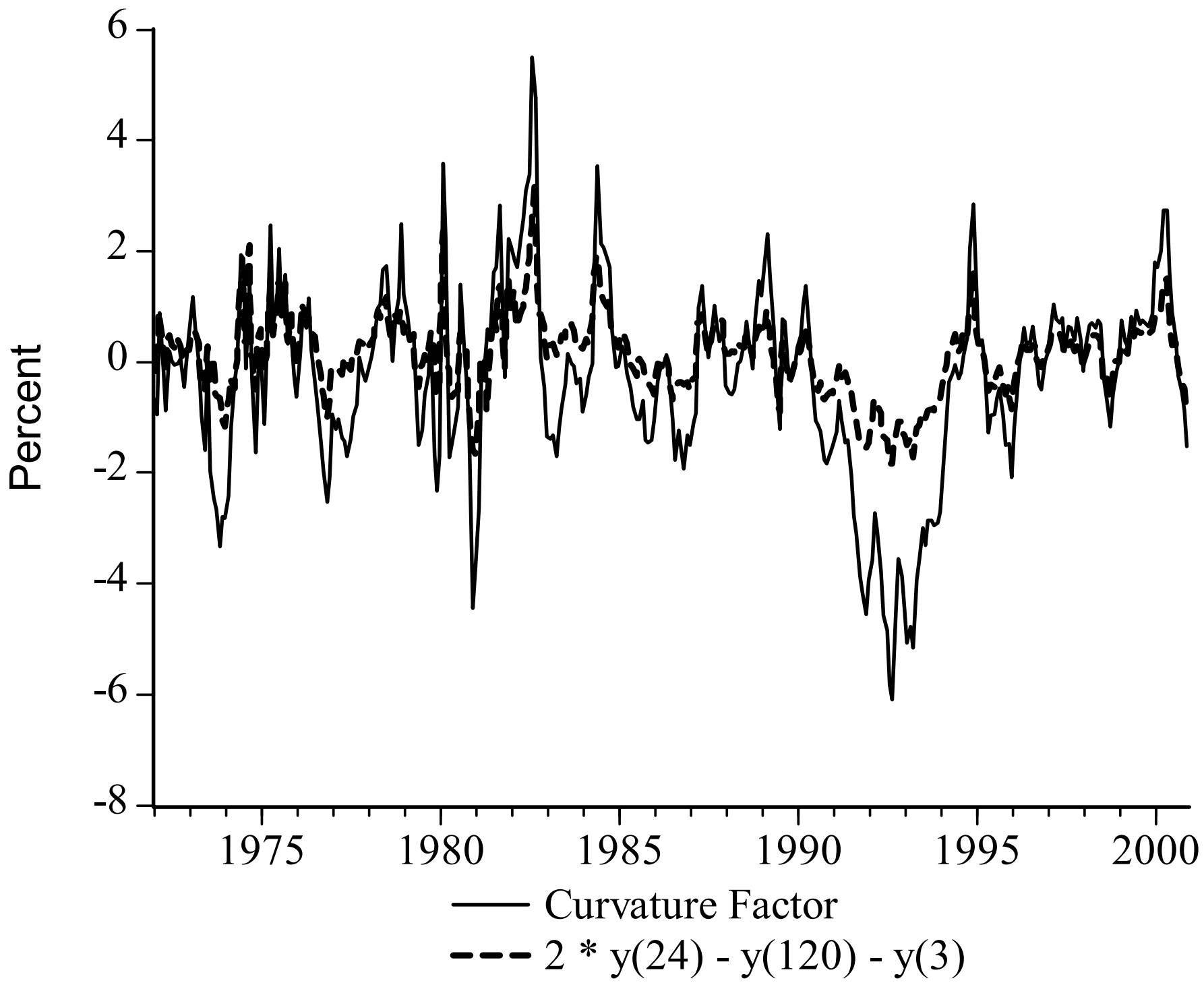


Figure 5

Impulse Responses of the Yields-Macro Model
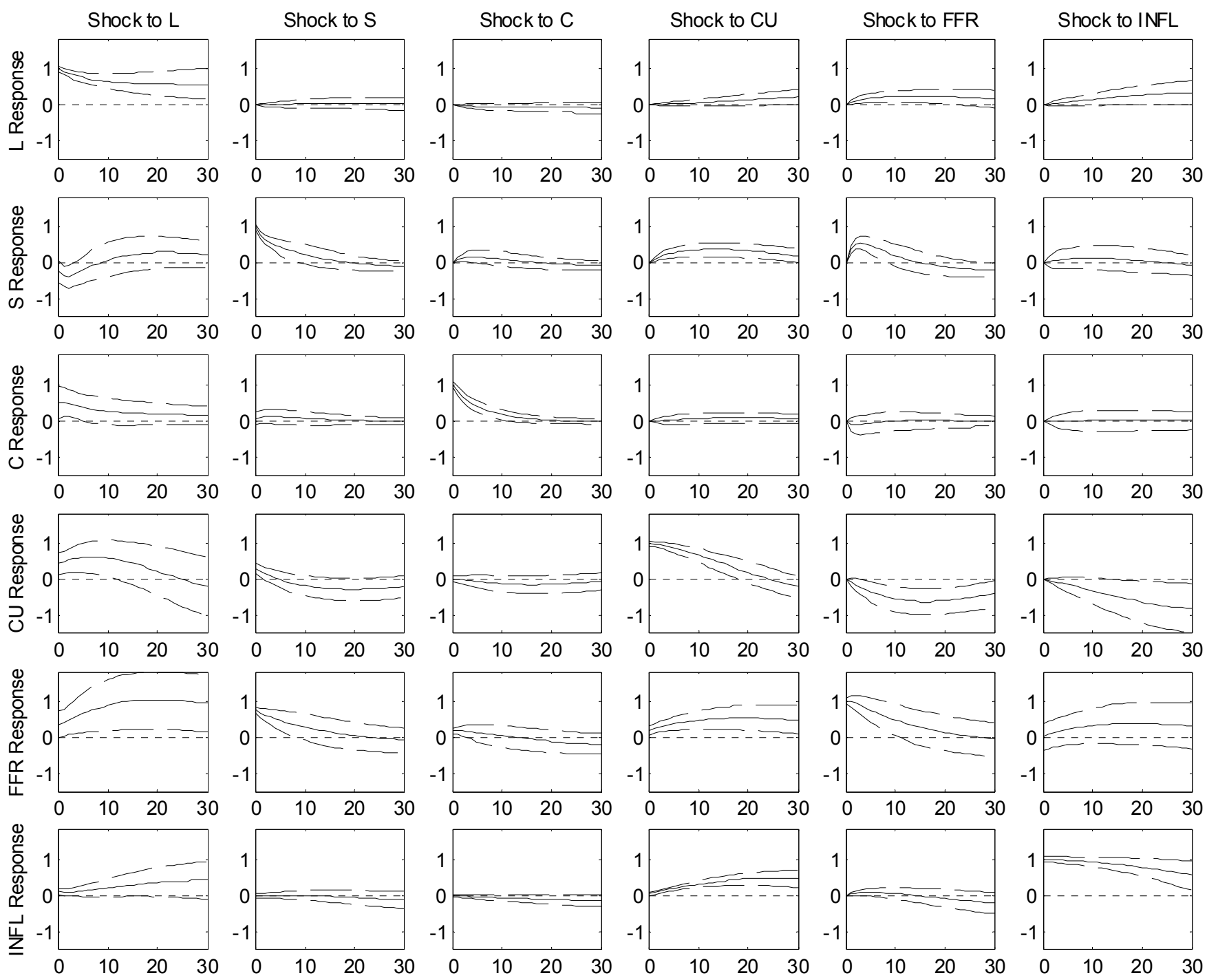


\section{Figure 6}

Impulse Responses of Yields-Macro Model

Diagonal $Q$ Point Model (Dashed), Non-Diagonal $Q$ Model with Confidence Interval Estimates (Solid)
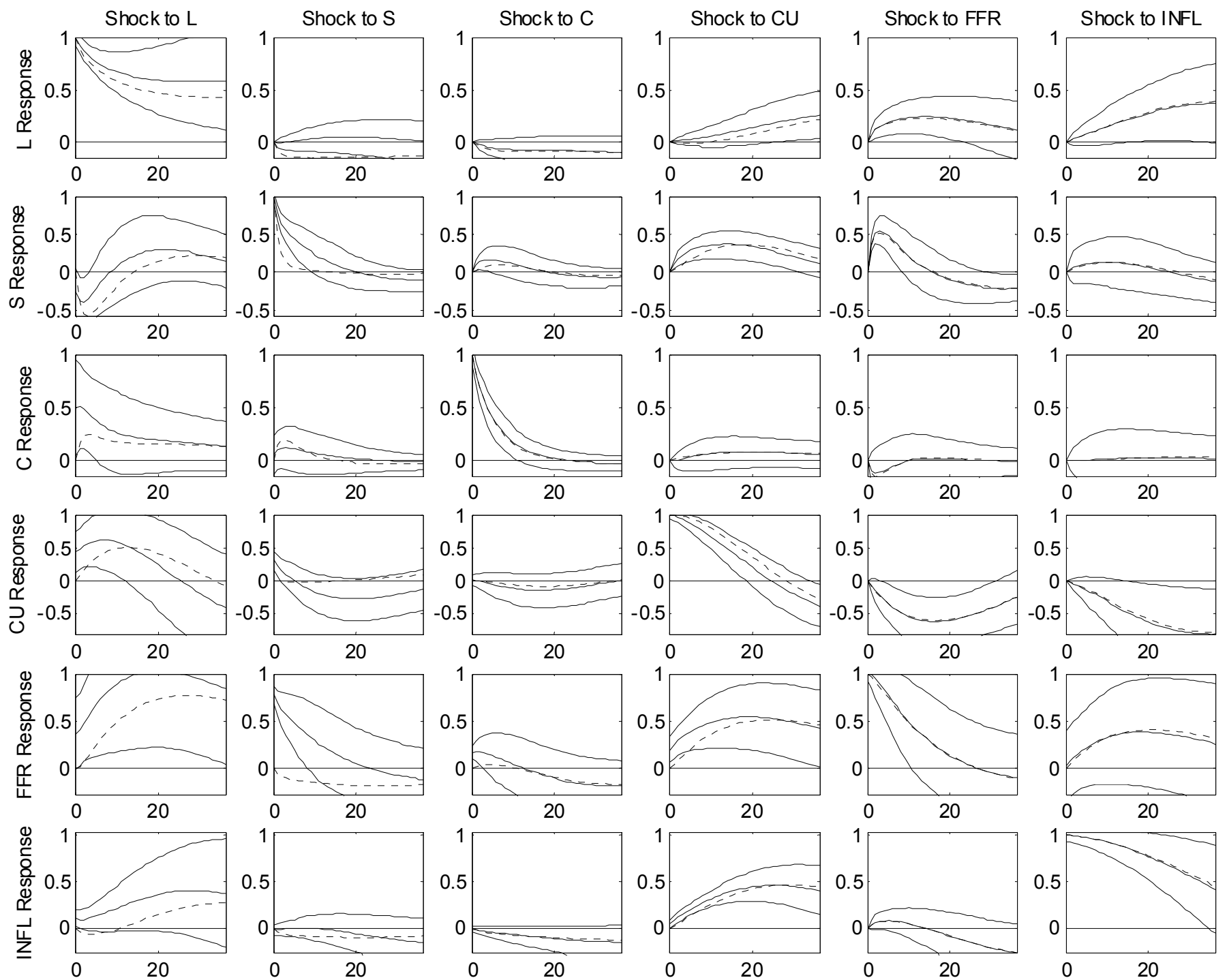
Figure 7

Actual Yields and Yields Implied by the Expectations Hypothesis
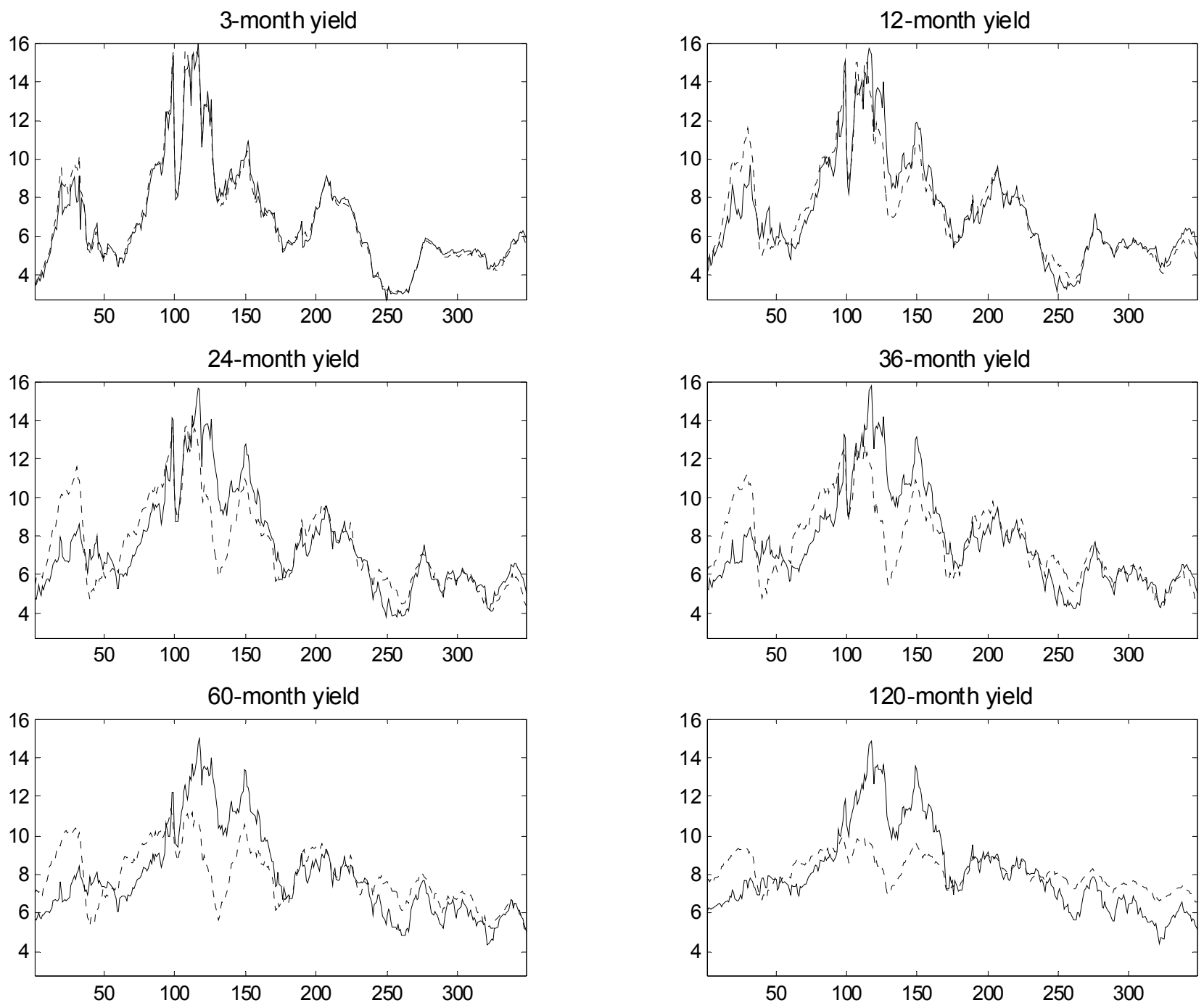

Notes : The actual yields are shown as solid lines. The yields implied by the expectations hypothesis are shown as dotted lines. 